\title{
Mudanzas e continuidades na estrutura económica de Galicia tras a crise financeira. Unha análise a través de táboas input-output (TIO) dos anos 2008 e 2016
}

\author{
Fernando de la Torre Cuevas* \\ Universidade de Santiago de Compostela - Facultade de Ciencias Económicas e Empresariais
}

Recibido: 23 de setembro de 2020 / Aceptado: 23 de novembro de 2020

\begin{abstract}
Resumo
O presente traballo investiga as mudanzas e as continuidades na estrutura económica de Galicia asociadas á crise iniciada no ano 2008 e ao posterior ciclo de recuperación. Abordaremos esta cuestión baixo o prisma da teoría crítica do desenvolvemento económico. Para iso, empregamos a información que nos proporcionan as táboas input-output dos anos 2008 e 2016, realizando un estudo comparativo delas. Comparamos, en primeiro lugar, os sectores claves que definen o núcleo da estrutura produtiva interior da economía galega. Seguidamente, estudamos as vantaxes e as desvantaxes comparativas da súa inserción exterior co resto de España, da Unión Europea e do mundo. Os resultados obtidos indican que a estrutura económica de Galicia non mudou, no fundamental, tras a crise económica. Este resultado empírico suxire que as causas do crecemento económico e da mellora no saldo da balanza comercial posteriores á crise deben ser buscadas noutro lugar.
\end{abstract}

\section{Palabras clave}

Desenvolvemento económico / Economía rexional / Input-Output / Relacións intersectoriais / Inserción externa.

\section{Changes and continuities in the Galician economic structure after the financial crisis. An analysis using the 2008 and 2016 input-output tables}

\begin{abstract}
The present work investigates the changes and continuities in the economic structure of Galicia during the 2008 crisis and the following economic recovery cycle. We will address this issue from the perspective of the critical perspective on economic development theory. To do so, we will use the information provided by the 2008 and 2016 input-output tables, carrying out a comparative analysis. In the first place, we compare the key sectors that define the core of the internal production scheme. After that, we study Galicia's comparative advantages and disadvantages of its external insertion in Spain, the European Union and the world. The results obtained indicate that the economic structure of Galicia has not changed in its fundamental aspects after the economic crisis. This result suggests that the causes of the economic growth and the improvement of the trade balance following the crisis must be looked for elsewhere.
\end{abstract}

\section{Keywords}

Economic development / Regional economics / Input-Output / Intersectoral relationships / External insertion.

JEL Codes: B51, B52, C67, F63.

\section{Introdución}

A crise iniciada no ano 2008 puxo de manifesto as débiles bases (López Hernández e Rodríguez López, 2010; Outes Ruso, 2012) sobre as que se asentou o crecemento económico español do período 1995-2007, provocando un retroceso en termos de xeración de riqueza, benestar e perspectivas para a

\footnotetext{
* Correspondencia autor: fernando.delatorre@usc.es
} 
maior parte da poboación. A recente publicación do Marco Input-Output de Galicia, correspondente ao ano 2016 (MIOGAL-16), facilita unha estatística detallada sobre as características que definen esta economía, pasado xa certo tempo desde os peores momentos do período de crise. Aproveitando a aparición desta información, o obxectivo desta investigación é analizar que mudanzas (e/ou continuidades) na estrutura económica de Galicia tiveron lugar durante o período de recesión e recuperación posterior. Entenderemos como estrutura económica o conxunto formado polas relacións intersectoriais e a inserción exterior (Kleiman, 1970) dun determinado espazo económico. Cabe destacar que, ata onde coñecemos, o presente traballo constitúe tamén a primeira análise, superficial iso si, dos datos ofrecidos polo MIOGAL-16. Ademais, discutiremos en que medida estas mudanzas ou continuidades poden relacionarse cun proceso de desenvolvemento económico rexional asociado á recuperación posterior á crise.

0 texto estrutúrase da seguinte maneira. No apartado de Materiais e métodos realizarase, en primeiro lugar, unha exposición das metodoloxías adoptadas á hora de realizar a investigación, xunto coas bases de datos empregadas. Estas comprenden, fundamentalmente, o coñecido como modelo de demanda de Leontief, o modelo de oferta de Ghosh e a súa aplicación concreta aos marcos input-output de Galicia correspondentes aos anos 2008 e 2016. En segundo lugar, exponse o marco teórico adoptado para a interpretación dos resultados. En concreto, adóptase unha definición do concepto de desenvolvemento económico baseada na achega de Leontief e relacionada co que se acoutará como paradigma crítico da teoría do desenvolvemento económico. A continuación, na sección terceira serán presentados os resultados empíricos obtidos a partir da análise comparativa entre as táboas input-output dos anos 2008 e 2016. Os datos expostos nesta sección serán resumidos e discutidos na sección cuarta, tendo en conta o marco teórico e conceptual xa mencionado. 0 apartado quinto resume as principais conclusións.

\section{Materiais e métodos}

\subsection{A análise input-output: o modelo aberto de demanda e de oferta}

A análise input-output xorde durante o primeiro terzo do século XX da man de Wassily Leontief (1906-1999) como metodoloxía construída para aprehender as relacións intersectoriais que determinan o desenvolvemento dunha determinada economía (Rose e Miernyk, 1989). No primeiro modelo elaborado por Leontief para a obtención do seu grao de doutor en 1927 (1991) e mais na primeira aplicación empírica deste analizando a economía norteamericana (1936), descríbense as estruturas económicas como sistemas de carácter circular e pechados, onde as diferentes ramas tanto produtivas como da demanda (os fogares) toman insumos e expiden producións de e cara ao resto de sectores. As relacións entre as diferentes ramas do sistema defínense a través dos coñecidos como coeficientes técnicos, os cales dan conta da proporción de insumo que a rama $j$ toma da rama $i$ para a produción dunha unidade de output:

$$
a_{i j}=\frac{x_{i j}}{X_{j}}
$$

Estes coeficientes recollen de maneira simultánea a estrutura tecnolóxica dunha economía e o sistema de prezos que nun momento dado asegura nela unha situación de equilibrio xeral (Moses, 1974). Por iso, para o estudo da evolución da estrutura produtiva de Galicia entre os anos 2008 e 2016 será preciso descontar a inflación diferencial entre os diferentes sectores desta economía.

Durante a II Guerra Mundial foi desenvolvéndose un novo modelo. Nel, por primeira vez, a demanda é considerada como unha variable esóxena, procurando mellorar a aplicabilidade do modelo para a política económica e para a súa acomodación no marco do sistema nacional de contas nortea- 
mericano (Kohli, 2001, pp. 199-203). 0 resultado destes traballos (Leontief, 1944) é o coñecido como "modelo aberto" de análise input-output. Tendo pola letra $Y$ a demanda, a produción dos diferentes sectores fica representada polo seguinte conxunto de ecuacións:

$$
\begin{aligned}
& \left(1-a_{11}\right) X_{1}-a_{12 \mathrm{X}} \mathrm{X}_{2}-\cdots-a_{1 n} X_{n}=Y_{1} \\
& -a_{21} X_{1}+\left(1-a_{22}\right) X_{2}-\cdots-a_{2 n} X_{n}=Y_{2} \\
& -a_{n 1} X_{1}-a_{n 2} X_{2}-\cdots+\left(1-a_{n n}\right) X_{n}=Y_{n}
\end{aligned}
$$

Este modelo, tamén coñecido como "modelo de demanda", relaciona "demandas finais autónomas e niveis de produción necesarios para satisfacelas" (Muñoz Cidad, 2000, p. 202). Para a resolución do sistema de ecuacións proposto polo modelo aberto, empregamos o coñecido algoritmo da inversa. En notación matricial, este sería da forma:

$$
x=(I-A)^{-1} y
$$

onde $x$ é o vector de produción das diferentes ramas da economía e $y$ o vector das súas correspondentes demandas finais. A demostración desta solución pode realizarse a través do coñecido como "método de sucesión de potencias" (Miller e Blair, 2009, pp. 31-34; Waugh, 1950). 0 significado dos elementos $\alpha_{i j}$ da inversa $(I-A)^{-1}$ de Leontief son interpretados como requirimentos directos e indirectos que a rama $j$ toma da rama $i$ para producir unha unidade máis de output (Guilhoto, 2001). A importancia deste xeito de proceder reside no feito de que establece as condicións para lograr unha situación de equilibrio xeral entre todas ramas produtivas dunha economía tras, por exemplo, un incremento $\Delta$ da demanda en calquera ou varias delas (Soza Amigo, 2007, p. 18). A solución ofrecida polo modelo é, ademais, única e non negativa (McKenzie, 1957).

De maneira análoga, partindo da mesma táboa simétrica podemos construír un modelo de oferta, coñecido tamén como modelo de Ghosh (1958), onde as tecnoloxías de produción se definen a través dos coñecidos como coeficientes de distribución $b_{i j}$. Estes obtéñense como cocientes entre a cantidade de mercadorías que a rama $i$ destina á rama $j$ e a demanda total (suma da demanda intermedia e final) da rama $i$ :

$$
b_{i j}=x_{i j} / X_{i}
$$

Seguindo a notación empregada para a solución do modelo de demanda de Leontief, en termos matriciais a solución do modelo de Ghosh é da forma:

$$
x^{T}=(I-B)^{-1} w
$$

onde $w$ é o vector de valores engadidos, que neste caso é a variable considerada como esóxena en substitución da demanda final, e $x^{T}$ o vector de producións de cada rama trasposto. Os elementos $\beta_{i j}$ da matriz inversa poden ser interpretados como os efectos facilitadores, directos e indirectos, para a produción do resto de ramas cando a produción da rama $i$ experimenta un incremento unitario. Esta proposta foi obxecto de severas críticas, e foi reinterpretada por Dietzenbacher (1977) como un modelo de prezos no marco do modelo de demanda antes considerado.

\subsection{Material empírico empregado: as táboas input-output de Galicia para os anos 2008 e 2016}

A elaboración de táboas input-output a nivel rexional no Estado español conta xa cunha certa traxectoria desde os inicios do desenvolvementismo franquista (del Castillo Cuervo-Arango, 1988). En 
Galicia, as primeiras táboas foron elaboradas para o ano 1970, e foron revisadas por Caballero Álvarez (1978). Posteriormente, foron realizadas as táboas input-output correspondentes aos anos 1980, 1990, 1998, 2005, 2008, 2011 e 20161. Á hora de estudar a armazón dunha determinada economía, as TIO ofrecen unha fonte estatística de gran calidade. Isto é así, en primeiro lugar, pola riqueza derivada da súa elaboración, ao achegar información sobre produción, intercambios internos de mercadorías, demanda final e comercio exterior moito máis detallada que a que nos ofrecen outras estatísticas. En segundo lugar, as TIO proporcionan unha concreción empírica dun modelo construído racionalmente a priori. As TIO son, pois, as que "enchen" o lugar baleiro que toda estrutura ou xuízo sintético ten, en principio, para poder aprehender correctamente a realidade (Villaverde López, 2014, p. 82). Por último, cómpre destacar que as TIO rexionais teñen o valor, ademais, de cumprir de maneira moito máis realista os supostos sobre os que se asenta o modelo aberto de demanda (McGregor, Swales e Ping Yin, 1996).

As TIO para Galicia empregadas na presente investigación corresponden aos anos 2008 e 2016. Estas táboas comparten a mesma Clasificación Nacional de Actividades Económicas para a súa elaboración (a CNAE-09). Para facelas totalmente comparables, son dúas as operacións que foron levadas a cabo. En primeiro lugar, procedeuse por agregación das filas e columnas correspondentes -seguindo en boa medida o método proposto por Leontief (1967)- a establecer unha clasificación única de sectores produtivos. A segunda cuestión abordada foi a da eliminación dos efectos da variación de prezos. Para iso, optouse polo enfoque proposto por Prado (2003), que consiste na deflación do valor das vendas realizadas polas diferentes ramas, xa sexa no mercado de bens intermedios ou no da demanda final interior e/ou exterior.

Tomando os datos do Índice de Prezos Industriais ofrecido polo Instituto Galego de Estatística (IGE) e do Índice de Volume Encadeados, construíuse un vector de prezos sectoriais interiores no que a base 100 é o ano 2016. Asumimos, neste caso, que este vector recolle as variacións nos prezos dos bens que conforman os custos de produción das diferentes mercadorías. Estes prezos sectoriais foron nivelados cos Índices de Volume Encadeados correspondentes aos mercados de bens intermedios, bens destinados ao consumo final das familias, das Administracións Públicas e a investimentos. Asumimos, así, que os prezos das mercadorías oscilan en torno ao seu custo de produción segundo as condicións de cada un dos diferentes mercados.

Por último, para o comercio exterior construíronse senllos vectores deflactores das importacións e das exportacións baseados nos Índices de Valor Unitario (IVU) do comercio exterior de Galicia, tamén facilitados polo IGE. Con estes datos elaboramos unha matriz de deflactores e dividimos a matriz simétrica e a matriz de demanda final a prezos correntes por aquela, co que se obteñen os datos medidos en euros do ano base, neste caso 2016. Os axustes para asegurar os equilibrios contables do modelo trasládanse ao vector de valor engadido, deflactándoo así implicitamente.

\subsection{Marco teórico para a análise dos resultados}

Para poder realizar unha análise coherente dos resultados empíricos obtidos, cómpre establecer unha definición máis ou menos precisa do concepto de desenvolvemento económico a fin de evitar que a opinión ou os prexuízos poidan erixirse como obstáculos epistemolóxicos (Bachelard, 1974). No seu artigo The Structure of Development, Leontief (1963) postulou que se se aspiraba a entender realmente o desenvolvemento e o subdesenvolvemento, cumpría ir máis alá de estatísticas globais agregadas como as taxas de crecemento do PIB ou as variacións nos saldos da balanza comercial nunha economía. Para este autor, o que caracteriza as estruturas económicas non desenvolvidas é o seu carácter incompleto e a súa estrutura excesivamente xerárquica, tanto referido á súa trama intersectorial como á súa inserción exterior.

\footnotetext{
${ }^{1}$ Agás a de 1980, todas as táboas poden ser consultadas na páxina web do Instituto Galego de Estatística. A maiores, esta institución ofrece a actualización parcial das táboas de orixe e destino de 2011 para o ano 2013. Consultar en: https://www.ige.eu/web/mostrar actividade estatistica.jsp?idioma=glecodigo $=0307007003$
} 
Esta definición de desenvolvemento económico enlaza co que Foster-Carter (1976) caracterizou como o paradigma crítico da teoría do desenvolvemento, seguindo o esquema para a análise da evolución do pensamento científico enunciado por Thomas Kuhn (1984). Este formúlase en contraposición ao paradigma hexemónico baseado, en maior ou menor medida, nas contribucións de Rostow (1956, 1963). As tres características principais, compartidas polos autores encadrados nesta liña de pensamento, poden resumirse no seguinte:

1. Rexeitamento dunha correspondencia unívoca entre a difusión do capital e das institucións capitalistas, e o avance das sociedades subdesenvolvidas.

2. Entender o fenómeno do subdesenvolvemento de determinadas economías como produto do desenvolvemento doutras.

3. Definir o camiño cara ao desenvolvemento non é comprendido como un proceso continuo e fatalista, senón como unha fase de ruptura necesaria cunha determinada posición dentro da división internacional do traballo.

A primeira destas formulacións atopámola na proposta dos economistas ligados á Comisión Económica para América Latina (CEPAL) da ONU. A Raúl Prebisch cabe atribuírlle a formulación da dicotomía centro-periferia para o estudo das relacións económicas internacionais e de como estas inflúen e interactúan coas estruturas económicas dos países atrasados (Couto, 2007). As estruturas económicas atrasadas, para este autor, caracterízanse por un progreso técnico tardío e irregular, sen ter en conta os recursos, potencialidades e necesidades dos territorios (Gurrieri, 1983; Prebisch, 1983). Pola súa banda, Celso Furtado enfocou o problema do subdesenvolvemento e da dependencia ao redor da incorporación incompleta das zonas económicas atrasadas á dinámica capitalista. Os sectores económicos incorporados ao capitalismo constituirían postos avanzados dentro dos países subdesenvolvidos. En contraposición, outras zonas periféricas fican illadas e xestionadas a través de institucións e lóxicas precapitalistas (con economías de subsistencia), destacando o feito de que estas operan como reservas de man de obra (Alves Cêpeda, 2005).

Nunha liña semellante, Paul Baran e Paul Sweezy observaron que as economías subdesenvolvidas deixaban cada vez máis de responder ao esquema colonial puramente extractivo, abrindo a porta á incorporación nelas de industrias maduras subordinadas aos grandes centros de decisión económica (Katz, 2016). Así mesmo, André Gunder Frank (1966) afirmou a posibilidade de que nos países e rexións da periferia capitalista estivese a darse un "desenvolvemento do subdesenvolvemento". O singular da súa análise radica en sinalar que a dinámica centro-periferia pode observarse non só entre os países avanzados e os menos avanzados, senón tamén, complementariamente, no interior destas unidades territoriais. Nesta liña, etiquetou o desenvolvemento das zonas economicamente menos avanzadas como un desenvolvemento "satelizado", o cal por definición non pode "concibirse a si mesmo nin asegurar a súa propia continuidade" (Frank, 1966, p. 22).

A través desta contribución podemos definir, entón, o que na presente investigación entenderemos como desenvolvemento económico, aproveitando a información cuantitativa achegada polas táboas input-output. Seguindo aos autores mencionados, non estableceremos unha correspondencia unívoca entre crecemento económico e mellora do saldo na balanza comercial, e desenvolvemento económico. O desenvolvemento económico implicará necesariamente, para os efectos deste traballo:

1. Que a estrutura económica analizada avance cara a unha composición sectorial máis completa.

2. A identificación dun maior número de nodos clave, ou fundamentais, que inflúan no seu comportamento.

Ademais, resulta pertinente desenvolver tamén, á luz do marco teórico exposto, unha análise de carácter cualitativa que observe a intensidade no emprego de tecnoloxía e de coñecemento por parte dos diferentes sectores e producións que se vaian analizar. 0 desenvolvemento económico, neste sentido, 
implicará unha maior sofisticación ou complexidade das producións dunha determinada economía (Felipe, Kumar, Abdon e Bacate, 2012; Gala, Camargo, Magacho e Rocha, 2018). As afirmacións realizadas sobre estas cuestións, iso si, deberán manter un carácter moito máis modesto e provisional.

\section{Resultados}

\subsection{Contexto macroeconómico}

En Galicia a crise supuxo, tamén, o final dun ciclo de crecemento sostido que se viña mantendo desde comezos de século, tanto se tomamos os datos en euros correntes como se descontamos o efecto dos prezos sobre a evolución do Produto Interior Bruto (Figura 1). A crise trouxo consigo, en termos nominais e reais, dúas recesións. A primeira delas, a máis aguda, tivo lugar no ano 2009. A segunda, con retrocesos un pouco máis suaves pero máis prolongada no tempo, comprendeu o período 2011-2013. Esta etapa de crise veu seguida dun novo ciclo de crecemento económico iniciado timidamente a partir do ano 2014. Os datos desde o ano 2016 deben ser tomados con cautela neste caso, dado o seu carácter aínda provisional. De calquera maneira, semella claro que, tras tocar fondo no ano 2013, a economía galega retomou en termos globais a senda do crecemento económico.

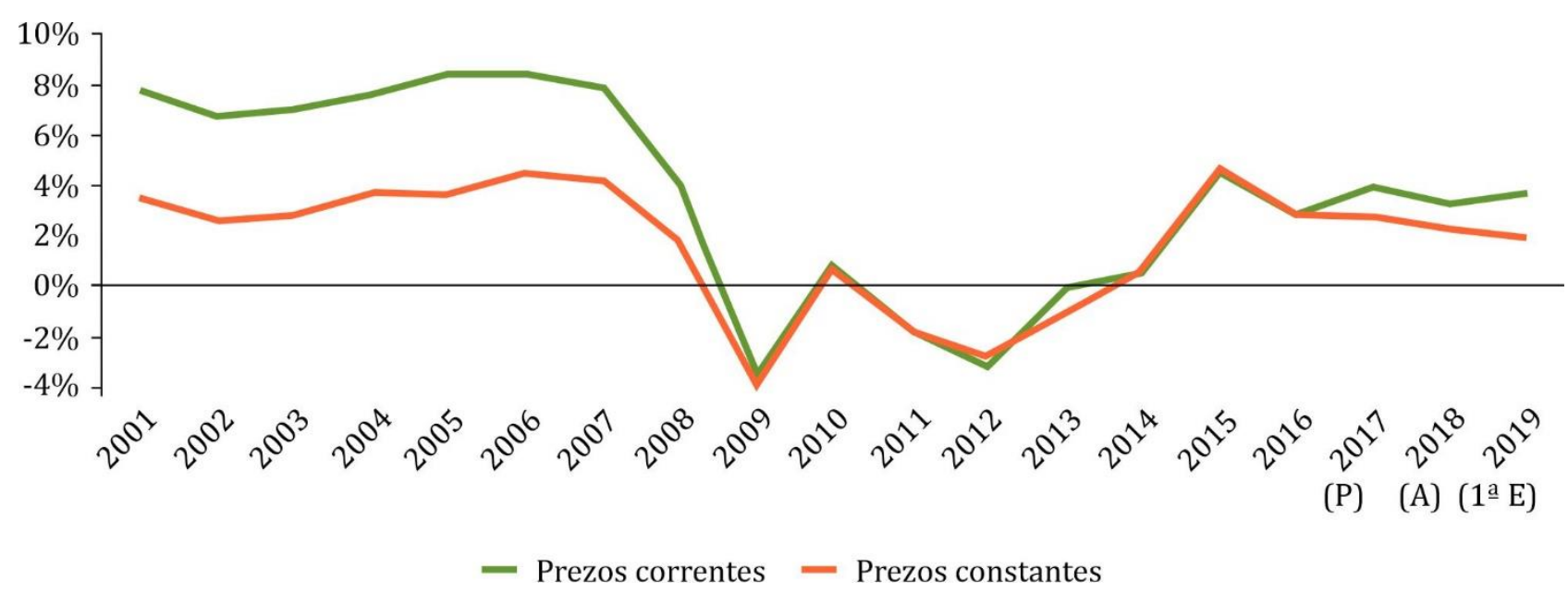

Figura 1. Taxas de variación anuais do PIB de Galicia a prezos correntes e a prezos constantes (euros de 2016). Anos 2001-2019. Fonte: elaboración propia a partir de INE, Contabilidad Regional de España.

En segundo lugar, a crise supuxo para Galicia a ruptura do proceso de converxencia en termos de renda per cápita que se viña dando, tanto coa media da Unión Europea (UE-28) como coa española, desde comezos do século XXI (Figura 2). No ámbito europeo, a posición relativa da economía galega viuse afectada de maneira máis clara, pasando de ser a súa renda per cápita o $89 \%$ da media comunitaria, no período 2007-2009, ao 82\% que supuña no ano 2018. Este feito contrasta coa clara tendencia cara á converxencia rexional de Galicia no ciclo de crecemento económico anterior, durante o cal o PIB per cápita pasou de supoñer o $76,2 \%$ da media da UE-28, no ano 2000 , ao $89,8 \%$ en 2007 . A crise trouxo como consecuencia un retroceso destacable dentro do marco europeo. A maiores, se consideramos a posición galega respecto dos espazos centrais da Unión (UE-15), a situación resulta aínda máis desfavorable. No ámbito estatal, o PIB per cápita galego mantívose estancado durante a última década en niveis próximos ao $90 \%$ da media, tras lograr durante os oito anos anteriores mellorar a súa posición relativa en 10 puntos porcentuais. 


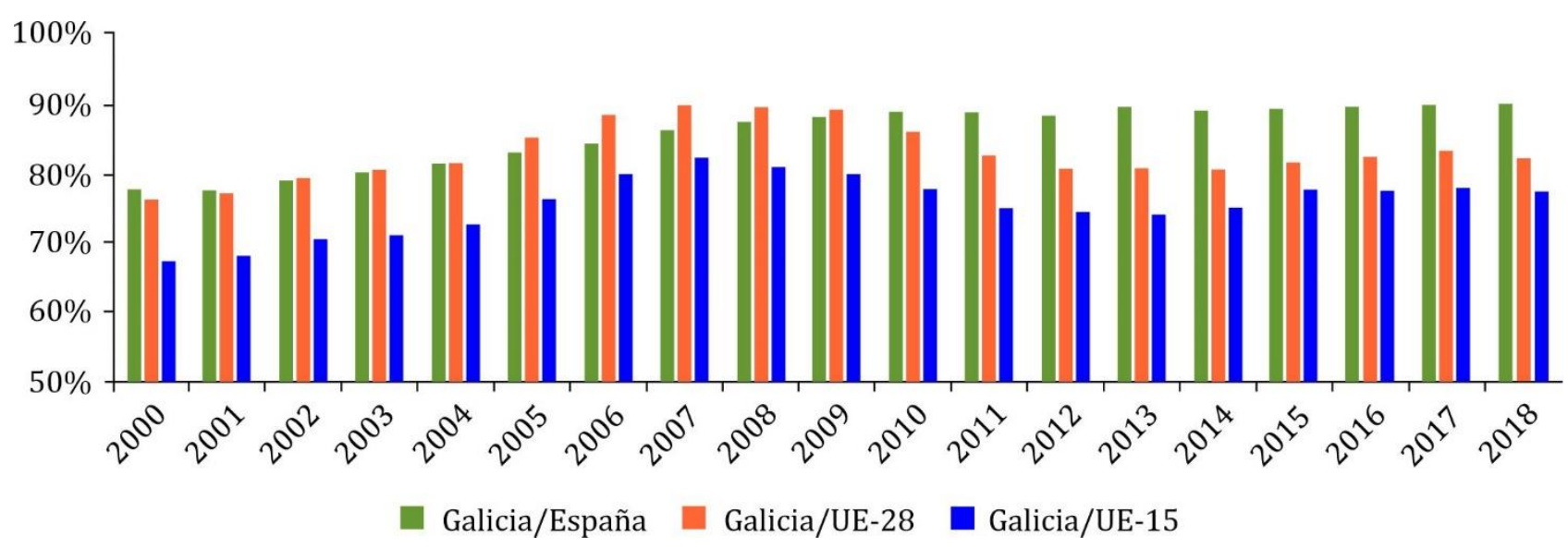

Figura 2. Converxencia do PIB (medido en Paridades de Poder Adquisitivo de 2020) per cápita de Galicia coa media de España, da UE-28 e da UE-15. Anos 2000-2018. Fonte: elaboración propia a partir de Eurostat Database, Gross domestic product (GDP) at current market prices by NUTS 2 regions.

No que á inserción externa se refire, podemos contextualizar as mudanzas na estrutura económica galega entre os anos 2008 e 2016 a través dos datos presentados nas Figuras 3 e 4 . Mediante as Contas Económicas de Galicia podemos constatar un claro cambio de tendencia tras a crise económica do ano 2008. Así, malia se manter o peso das exportacións sobre o PIB no arredor do 50\%, a taxa de cobertura global da economía galega aumentou en 20 puntos, pasando de pouco menos do 80\%, no ano 2008, a unha situación de equilibrio oito anos máis tarde. A crise tivo como consecuencia a redución da dependencia de Galicia, respecto da súa contorna, á hora de satisfacer a súa demanda interna.

Por ámbitos xeográficos, a economía galega pasou de presentar déficits nas súas balanzas comerciais co resto de España e co resto da UE a gozar dunha situación de superávit no ano 2016. Xa que logo, observamos, en principio, unha mellora da situación competitiva global de Galicia nos contextos estatal e comunitario.

Pola súa banda, a taxa de cobertura no comercio co resto do mundo experimentou, tamén, un crecemento de case 25 puntos porcentuais, pese a seguir presentando unha situación deficitaria tras a crise.

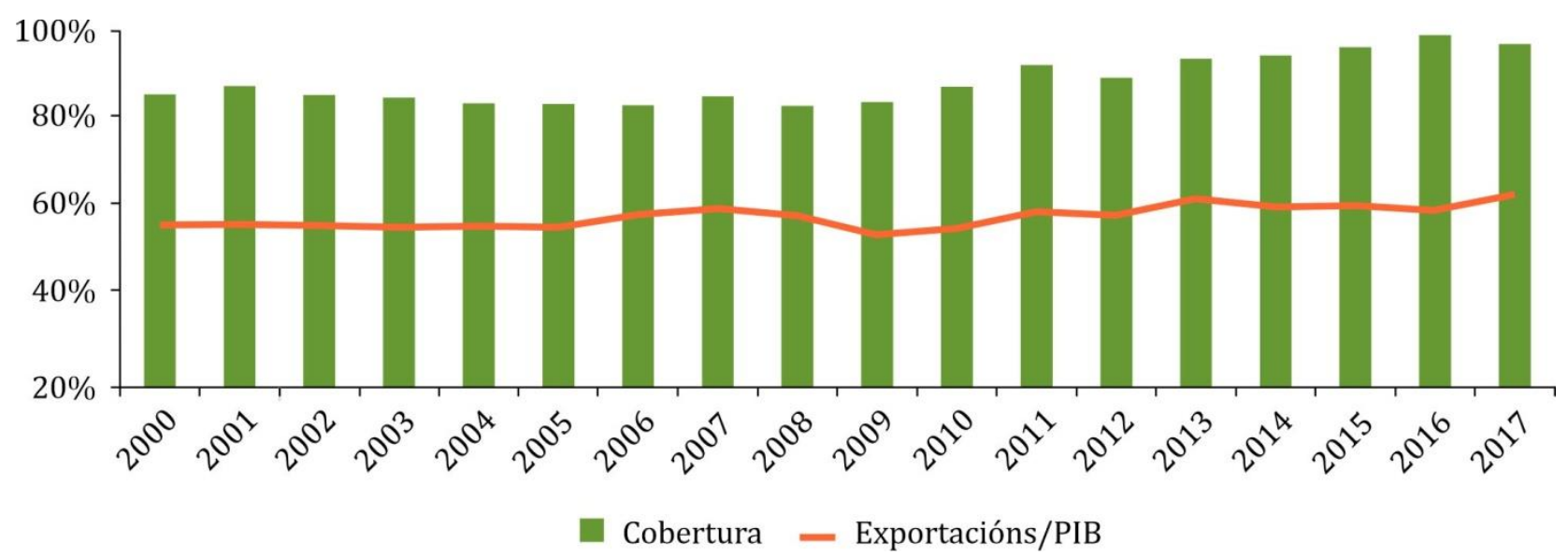

Figura 3. Evolución da taxa de cobertura (eixe dereito) e do peso das exportacións sobre o PIB en Galicia (eixe esquerdo). Anos 2000-2017. Fonte: elaboración propia a partir de IGE, Contas Económicas de Galicia. Revisión Estatística 2019. 


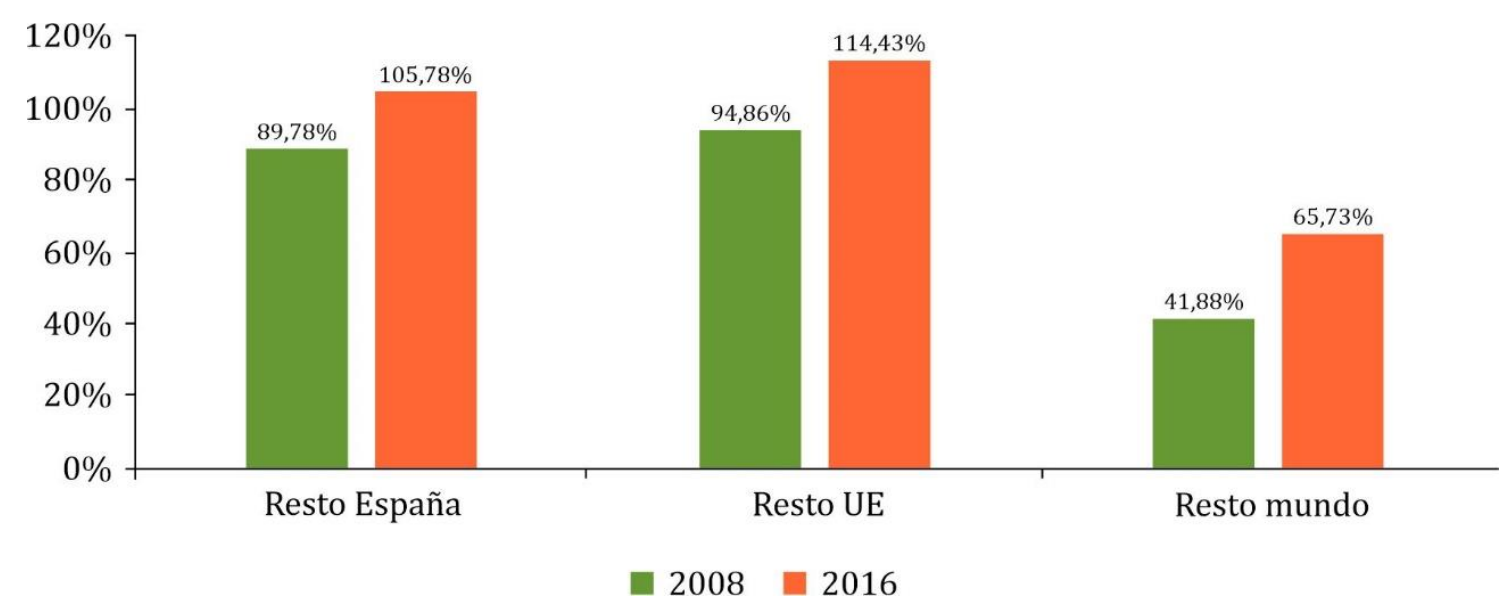

Figura 4. Taxa de cobertura da economía galega respecto do resto de España, do resto da UE e do resto do mundo. Anos 2008 e 2016. No caso da Unión Europea, para o ano 2008 tómase a UE-27 e para o ano 2016, a UE-28. Fonte: elaboración propia a partir de IGE, Marco input-output de Galicia anos 2008 e 2016.

\subsection{Evolución das relacións intersectoriais}

\subsubsection{Metodoloxía específica: identificación de sectores clave, básicos, motores e independentes}

Seguindo o método proposto tanto por Fernández Fernández e Fernández Grela (2003) como polo propio IGE (2010), para a análise das relacións intersectoriais utilizamos unha versión dos coñecidos índices de Rasmussen (1956). No estudo dos encadeamentos cara atrás empregamos o índice de poder de dispersión. Este defínese para a rama $j$ dunha economía como:

$$
U_{j}^{P}=\frac{\frac{\sum_{i} \alpha_{i j} D_{i}}{\sum_{i} D_{i}}}{\left(\frac{1}{n}\right) * \sum_{j} \frac{\sum_{i} \alpha_{i j} D_{i}}{\sum_{i} D_{i}}}
$$

onde $\alpha_{i j}$ é un elemento da matriz inversa de Leontief e $D_{i}$ o valor da demanda final da rama $i$ da produción galega. Deste xeito, no numerador temos a utilización media que a rama $j$ fai de produtos doutras ramas e no denominador, o valor medio dos coeficientes do numerador. Así pois, se o valor de $U_{j}{ }^{P}$ é maior que 1 , indicará que a rama $j$ ten un poder de dispersión (e, polo tanto, unhas ligazóns ponderadas cara atrás con outras ramas) superior á media.

Para os encadeamentos cara adiante, os índices de sensibilidade de dispersión son definidos de maneira análoga como:

$$
U_{i}^{S}=\frac{\frac{\sum_{j} \beta_{i j} D_{j}}{\sum_{j} D_{j}}}{\left(\frac{1}{n}\right) * \sum_{i} \frac{\sum_{j} \beta_{i j} D_{j}}{\sum_{j} D_{j}}}
$$

onde $\beta_{i j}$ é un elemento da matriz inversa de Ghosh (modelo de oferta) e $D_{j}$ o valor da demanda final da rama $j$ na produción galega. Seguindo a explicación do índice de poder de dispersión, no numerador temos o valor medio do que outras ramas empregan da rama $i$ e no denominador, o valor medio dos coeficientes do numerador. Se o valor de $U_{i}^{S}$ é superior a 1, isto indica que a rama $i$ ten unha sensibilidade de dispersión (e, polo tanto, unhas ligazóns ponderadas cara adiante) superior á media. 
A partir dos valores de ambos os índices, é posible construír unha tipoloxía de sectores na que se ten en conta o seu peso na demanda final e a intensidade das relacións tecnolóxicas con outros sectores de actividade. Os sectores económicos fican encadrados nestas catro categorías:

-Sectores claves: aqueles que presentan valores superiores á unidade para os dous índices. Son importantes demandantes e oferentes no interior dunha economía, e constitúen os nodos fundamentais da súa estrutura produtiva.

-Sectores básicos: presentan valores superiores á unidade para o índice de sensibilidade de dispersión, pero menores que a unidade para o índice de poder de dispersión. Trátase de sectores cuxa produción fica orientada cara á demanda intermedia.

-Sectores motores: presentan valores superiores á unidade para o índice de poder de dispersión, pero menores á unidade para o índice de sensibilidade de dispersión. Estamos ante sectores orientados cara á demanda final, e por iso con encadeamentos febles cara adiante, pero con fortes ligazóns como demandantes de inputs intermedios doutras ramas.

-Sectores independentes: rexistran valores menores que a unidade para ambos os índices, e polo tanto están pouco relacionados co resto dos sectores desa economía. Constitúen as "ausencias" dunha determinada estrutura económica.

Tomando como base para o cálculo dos índices os coeficientes interiores, o resultado desta clasificación cataloga as ramas segundo o seu grao de integración no aparello produtivo da economía que nos propoñemos estudar, dando conta dos nodos fundamentais na súa estrutura interna.

\subsubsection{Situación de partida: sectores fundamentais e “ausencias" dentro da estrutura produtiva galega no ano 2008}

A Figura 5 resume a posición de cada unha das 71 ramas produtivas consideradas seguindo a tipoloxía de sectores exposta e baseada nos índices de Rasmussen. Nas Táboas A.1, A.2, A.3 e A.4 do Anexo pode atoparse unha comparativa entre sectores claves, básicos, motores e independentes tanto para o ano 2008 como para o 2016. De aquí en adiante, cando citemos a denominación específica que recibe unha rama produtiva no marco das TIO, farémolo sempre comezando en letra maiúscula para a súa distinción.

A estrutura produtiva de Galicia, no momento inmediatamente anterior ao inicio da crise, asentábase arredor de catro piares fundamentais:

1. A construción. 0 papel da construción dentro da trama intersectorial de Galicia no ano 2008 fica acreditado pola presenza entre as ramas clave da economía galega dos sectores de Construción e Actividades inmobiliarias. A estas cabe engadir a presenza das Actividades de saneamento e xestión de residuos de non mercado, dentro dos sectores motores, e a da Fabricación doutros produtos minerais non metálicos, dentro dos sectores básicos, ambas claramente ligadas ao devir deste tipo de actividades.

2. Os servizos de carácter tradicional e rutineiro. En segundo lugar, destaca o papel fundamental que desempeña un bo número de ramas de servizos tradicionais. Dentro deste apartado, destacan como sectores claves as dúas ramas ligadas ao comercio (por xunto e polo miúdo) e os Servizos de comidas e bebidas. A maiores, como sectores básicos da economía galega no ano 2008, temos as ramas de Transporte terrestre e por tubaxe, Almacenamento e actividades anexas ao transporte, Actividades de alugueiro, Actividades postais e de correo, Actividades relacionadas co emprego (empresas de traballo temporal), etcétera. Xunto a elas, aparecen de maneira tímida unhas poucas ramas ligadas a servizos a empresas, como son as de Actividades xurídicas e contables, servizos financeiros, Telecomunicacións, Publicidade e estudos de mercado e as de Servizos de arquitectura e enxeñaría; ensaios e análise técnica. Nótese que, coa excepción das dúas últimas ramas, se trata de servizos intensivos en coñecemento e de carácter xeralmente rutineiro. 
3. Industria de intensidade tecnolóxica media e baixa. No ámbito industrial, dentro dos sectores claves cabe sinalar, en primeiro lugar, o papel da Fabricación de vehículos de motor, remolques e semirremolques, claramente ligada á factoría de PSA-Citröen en Vigo. Xunto a esta rama, aparece a Fabricación doutro material de transporte, onde queda encadrada a construción naval, que no ano 2008 aínda ocupa un papel destacado como sector motor. En segundo lugar, temos as ramas vencelladas ao sector enerxético de Coquerías e refino de petróleo, e de Fornecemento de enerxía eléctrica, gas, vapor e aire acondicionado. A maiores, dentro dos sectores industriais claves na economía galega de 2008 atopamos unha rama dedicada á elaboración de subministracións industriais de escasa intensidade tecnolóxica como é a da Metalurxia (onde se encadra a produción de aluminio). Outras industrias de semellante cometido, como a Fabricación de produtos de caucho e plásticos e a Fabricación de produtos metálicos agás maquinaria e equipamento, aparecen tamén dentro dos sectores básicos. Existen, así mesmo, na estrutura produtiva galega do ano 2008 outras industrias que, se ben non teñen a consideración de sectores clave, desempeñan un importante papel. Estas son as ramas ligadas á Industria alimentaria (produtos lácteos, procesamento e conservación de carne e de peixes, etc.), que operan como sectores motores, e as Industrias extractivas, que aparecen como sector básico.

4. O sector público. Por último, non pode deixar de destacarse a función que o sector público ten na economía galega anterior á crise económica. Esta queda reflectida coa presenza da rama de Administración pública e sanidade de non mercado, dentro dos sectores claves, e tamén co papel do Ensino de non mercado, como sector motor. Ademais, a importancia do sector público esténdese por mor da súa elevada capacidade para influír no devir doutras ramas de actividade, como as da Sanidade de mercado ou as de Actividades de saneamento e xestión de residuos.

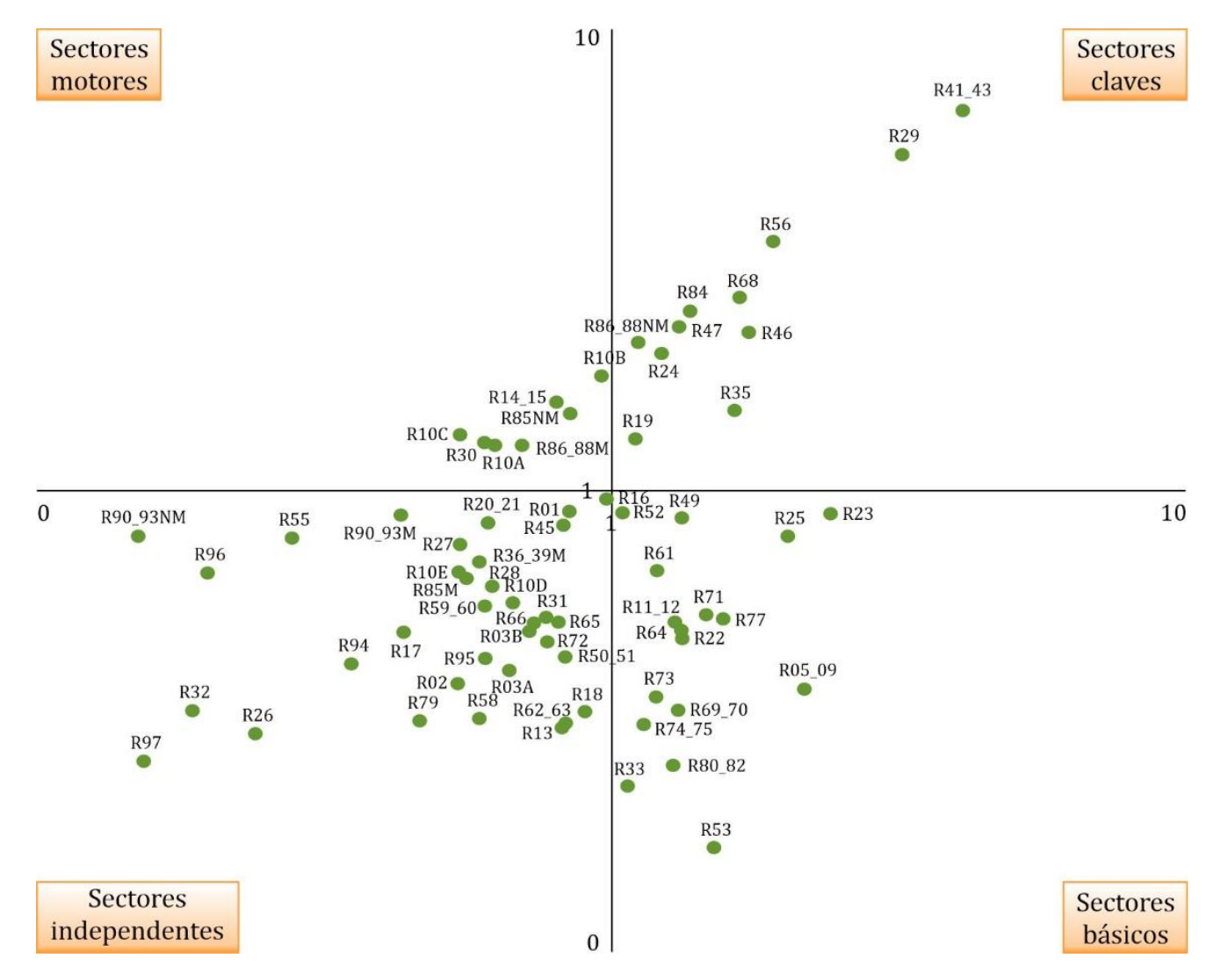

Figura 5. Sectores claves, motores, básicos e independentes na economía galega. Ano 2008. Fonte: elaboración propia a partir de IGE, Marco input-output de Galicia ano 2008. 
No plano das "ausencias" dentro da estrutura produtiva galega, recollidas no cuadrante dos sectores independentes, distínguense tres grandes bloques de ramas económicas. En primeiro lugar, obsérvanse escasas ligazóns ponderadas de varios servizos intensivos en coñecemento de carácter punteiro. Poden sinalarse aquí as ramas de Actividades cinematográficas, Artes gráficas, Edición, Investigación e desenvolvemento, e a de Programación, consultaría e outras actividades relacionadas coa informática; servizos de información, entre outras. En segundo lugar, cómpre comentar a presenza, dentro dos sectores independentes, de certas ramas industriais vencelladas a producións de tecnoloxía media-alta e alta como son a Fabricación de maquinaria e equipamento, a de Material e equipo eléctrico, Produtos informáticos, electrónicos e ópticos, e Química e produtos farmacéuticos. Ademais, observamos o papel relativamente secundario que ocupaban na estrutura produtiva galega anterior á crise as ramas primarias, consideradas sectores independentes, como a Agricultura, gandaría, caza e servizos relacionados con elas, a Silvicultura e explotación forestal, a Pesca e a Acuicultura.

\subsubsection{Cambios tras a crise económica. Ano 2016}

A primeira cuestión que cómpre salientar na comparativa entre as TIO galegas de 2008 e 2016 é a caída do peso relativo dos sectores menos conectados coa estrutura produtiva galega (os independentes), en termos de produción e emprego, fronte a aqueles que presentan vínculos de maior intensidade no seu requirimento e/ou na distribución do seu output (Táboa 1). Destaca, tamén, que a porcentaxe de produción e emprego perdida por esta tipoloxía de ramas non se distribúe homoxeneamente entre sectores claves, básicos e motores, senón que son as ramas claves as máis beneficiadas. 0 resultado deste período de recesión e estancamento económico foi o reforzo das posicións na produción interior e no emprego daquelas actividades económicas capaces de construír redes relativamente densas de interaccións con outros sectores.

A trama produtiva saída da crise, e reflectida na TIO de 2016, mantén como fundamentais os catro piares observados para 2008: a construción, os servizos de carácter tradicional, unha industria de intensidade tecnolóxica media ou baixa e a acción do sector público (Figura 6). No capítulo das continuidades, en primeiro lugar e malia ser o sector máis golpeado pola crise iniciada en 2008, a Construción e as Actividades inmobiliarias manteñen o seu papel como sectores claves. No capítulo dos servizos, cabe resaltar, como novidade, a incorporación desde os sectores independentes das Actividades artísticas, recreativas e de entretemento de mercado e das Actividades auxiliares aos servizos financeiros e aos seguros. No eido industrial, a Industria da madeira e da cortiza, agás mobles; cestaría e espartaría aparece como sector motor, cando en 2008 era considerado independente. 0 sector público ve reforzada a súa importancia, directamente coa incorporación da rama do Ensino de non mercado aos sectores claves (antes motor), e indirectamente coa inclusión do sector de Subministración de auga, actividades de saneamento, xestión de residuos e descontaminación de mercado aos sectores motores.

Táboa 1. Evolución do peso relativo da produción (produción interior a prezos básicos) e do emprego (postos de traballo equivalentes) dos sectores claves, básicos, motores e independentes. Anos 2008 e 2016

\begin{tabular}{lccccc}
\hline & \multicolumn{2}{c}{ Produción } & & \multicolumn{2}{c}{ Emprego } \\
\cline { 2 - 3 } \cline { 5 - 6 } & 2008 & 2016 & & 2008 & 2016 \\
\hline Sectores claves & $51,54 \%$ & $61,01 \%$ & & $44,69 \%$ & $58,39 \%$ \\
Sectores básicos & $17,80 \%$ & $16,75 \%$ & & $19,73 \%$ & $16,52 \%$ \\
Sectores motores & $11,97 \%$ & $8,60 \%$ & & $11,32 \%$ & $4,88 \%$ \\
Sectores independentes & $18,69 \%$ & $13,63 \%$ & & $24,25 \%$ & $20,21 \%$ \\
\hline
\end{tabular}

Fonte: elaboración propia a partir de IGE, Marco input-output de Galicia anos 2008 e 2016. 
Dúas son as principais mudanzas observadas. A primeira delas atopámola na inclusión dun "quinto piar", constituído polas ramas primarias. 0 sector de Agricultura, gandaría, caza e servizos relacionados con elas pasa de ser considerado independente en 2008 a clave en 2016, e a rama da Pesca fica incluída como sector básico. Refórzase, desta maneira, a importancia do complexo agro-mar-industria. Pola contra, a rama de Fabricación doutro material de transporte pasa a estar clasificado no capítulo de sectores independentes da estrutura produtiva galega, o cal é síntoma do declive no sector da construción naval.

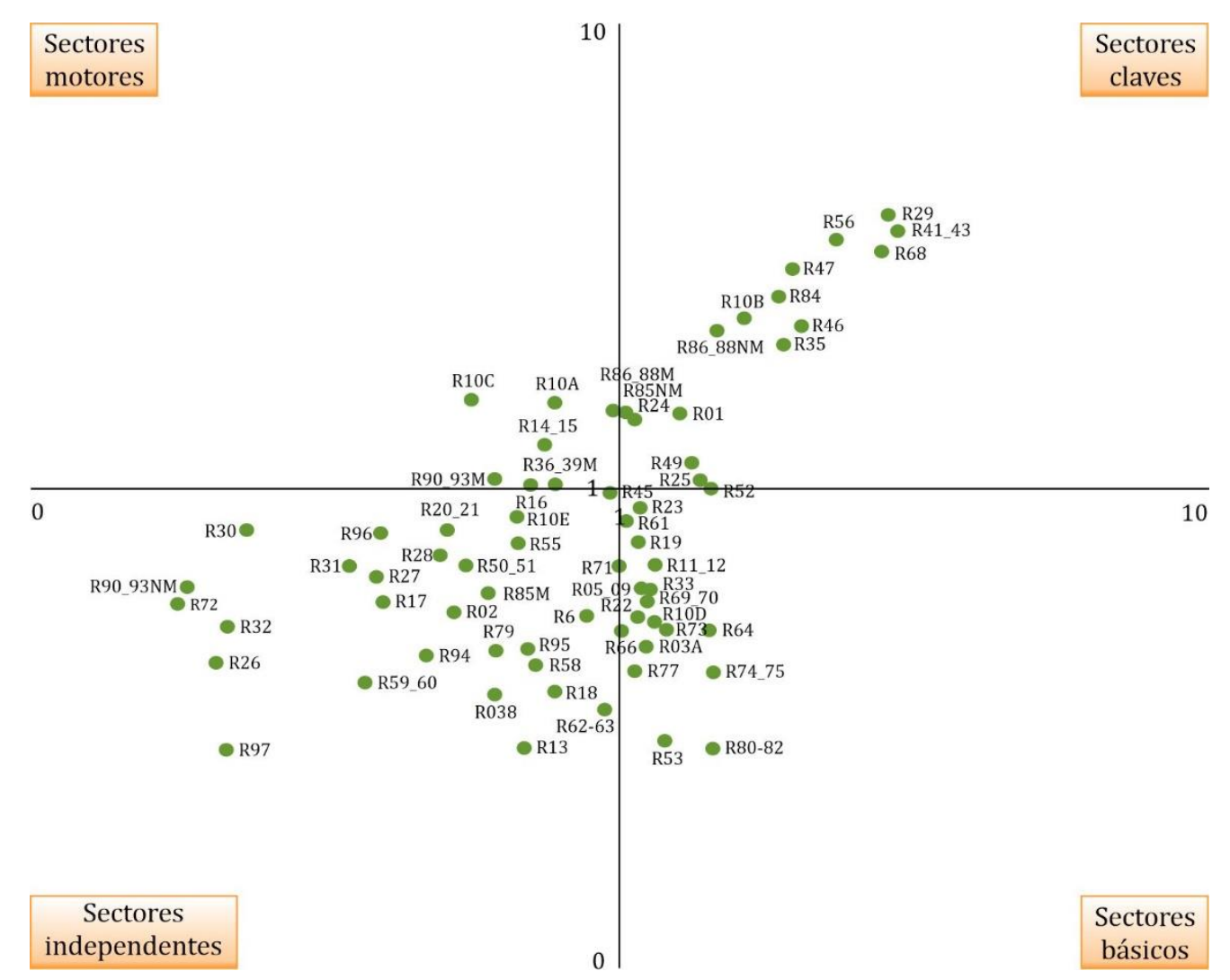

Figura 6. Sectores claves, motores, básicos eindependentes na economía galega. Ano 2016. Fonte: elaboración propia a partir de IGE, Marco input-output de Galicia ano 2016.

Os ocos baleiros dentro da estrutura produtiva de Galicia tras a crise económica continúan estando protagonizados, en boa medida, polos servizos máis intensivos no emprego de coñecemento e polas ramas industriais de maior intensidade tecnolóxica. Nesta liña, destaca a incorporación aos sectores independentes en 2016 da rama de Servizos técnicos de arquitectura e enxeñería; ensaios e análise técnica. Detectamos, por tanto, que a pesar de que cuantitativamente os sectores independentes dentro da economía galega viron reducido o seu peso, dentro deles seguimos atopando boa parte das ramas máis dinámicas á hora da xeración, captación e emprego económico de novos coñecementos.

\subsection{Evolución da inserción exterior da economía galega}

Partindo da base de que a inserción exterior dunha determinada economía é reflexo da súa estrutura sectorial, procuraremos analizar se esta segue un patrón común no ámbito interrexional e no inter- 
nacional ou se, pola contra, podemos observar dinámicas diferenciadas. Realizamos esta aproximación máis detallada calculando os Índices de Vantaxe Comparativa Revelada (IVCR) (Táboa 2). Tomando a metodoloxía empregada polo IGE (2010, p. 28), definimos para un determinado produto $i$ e un ámbito xeográfico $A$ o índice de vantaxe comparativa revelada como:

$$
I V C R_{i}=\left(\frac{X_{i}^{A}-M_{i}^{A}}{X^{A}+M^{A}}\right) * 100
$$

onde $X$ son as exportacións e $M$ son as importacións. Así, o saldo entre exportacións e importacións de cada produto pondérase polo seu peso relativo nos intercambios totais que a economía galega realiza cun determinado ámbito xeográfico (resto do Estado español, resto da Unión Europea ou resto do mundo). Por definición, os seus valores moveranse entre 100 e -100. A modo de exemplo, o valor 100 suporía a existencia de comercio cun ámbito xeográfico monopolizado por un só produto, do cal non se realiza ningunha importación. Neste caso, tomaremos os datos das matrices de orixe e destino a prezos básicos dos correspondentes marcos input-output. Os índices serán calculados a prezos correntes, dado que o que nos interesa é observar a posición galega nos mercados español, europeo e mundial, e non tanto o papel tecnolóxico que desempeña o comercio no interior do tecido produtivo.

Táboa 2. Produtos con maiores e menores IVCR na economía galega. Anos 2008 e 2016

\begin{tabular}{|c|c|c|c|c|c|}
\hline \multicolumn{6}{|c|}{ Maiores índices } \\
\hline Código & Produto & 2008 & Código & Produto & 2016 \\
\hline $29 \mathrm{~A}$ & Vehículos de motor. & 6,92 & $29 \mathrm{~A}$ & Vehículos de motor. & 6,60 \\
\hline $30 \mathrm{~A}$ & Construción naval. & 2,10 & 10B2 & $\begin{array}{l}\text { Conservas (pescado, moluscos e crustá- } \\
\text { ceos). }\end{array}$ & 3,58 \\
\hline 10B2 & $\begin{array}{l}\text { Conservas (pescado, moluscos e crustá- } \\
\text { ceos). }\end{array}$ & 2,01 & 46 & $\begin{array}{l}\text { Servizos de comercio por xunto e in- } \\
\text { termediarios, agás de vehículos de mo- } \\
\text { tor. }\end{array}$ & 2,58 \\
\hline 46 & $\begin{array}{l}\text { Servizos de comercio por xunto e in- } \\
\text { termediarios, agás de vehículos de mo- } \\
\text { tor. }\end{array}$ & 1,74 & $35 \mathrm{~A}$ & $\begin{array}{l}\text { Servizos de produción, transporte e dis- } \\
\text { tribución de enerxía eléctrica. }\end{array}$ & 1,95 \\
\hline $35 \mathrm{~A}$ & $\begin{array}{l}\text { Servizos de produción, transporte e dis- } \\
\text { tribución de enerxía eléctrica. }\end{array}$ & 1,44 & 01B & Produtos gandeiros. & 1,21 \\
\hline 14 & Pezas de roupa. & 1,17 & 14 & Pezas de roupa. & 1,07 \\
\hline $16 \mathrm{~B}$ & Outros produtos de madeira. & 0,84 & $16 \mathrm{~B}$ & Outros produtos de madeira. & 0,97 \\
\hline 01B & Produtos gandeiros. & 0,78 & 52 & Servizos anexos ao transporte. & 0,92 \\
\hline $10 \mathrm{C} 1$ & Leite de consumo líquido e en po. & 0,72 & $24 \mathrm{~A}$ & $\begin{array}{l}\text { Aluminio, outros produtos metais non } \\
\text { férreos e metais preciosos. }\end{array}$ & 0,92 \\
\hline 23D & $\begin{array}{l}\text { Pedra tallada, labrada e acabada, manu- } \\
\text { facturas de pedra. }\end{array}$ & 0,48 & $47 \mathrm{~A}$ & $\begin{array}{l}\text { Servizos de comercio polo miúdo agás } \\
\text { de vehículos de motor e de combustible } \\
\text { para vehículos de motor. }\end{array}$ & 0,82 \\
\hline
\end{tabular}


Táboa 2 (continuación). Produtos con maiores e menores IVCR na economía galega. Anos 2008 e 2016

\begin{tabular}{|c|c|c|c|c|c|}
\hline \multicolumn{6}{|c|}{ Menores índices } \\
\hline Código & Produto & 2008 & Código & Produto & 2016 \\
\hline $01 \mathrm{~A}$ & Produtos agrícolas & $-0,88$ & $10 \mathrm{E} 2$ & Aceites e graxas vexetais e animais & $-0,89$ \\
\hline 73 & $\begin{array}{l}\text { Servizos de publicidade e estudos de } \\
\text { mercado }\end{array}$ & $-0,91$ & $62 \_63$ & $\begin{array}{l}\text { Servizos de programación, consultaría } \\
\text { e outros servizos relacionados coa in- } \\
\text { formática; servizos de información }\end{array}$ & $-0,90$ \\
\hline $10 \mathrm{E} 4$ & Outros produtos alimenticios & $-0,93$ & 73 & $\begin{array}{l}\text { Servizos de publicidade e estudos de } \\
\text { mercado }\end{array}$ & $-1,00$ \\
\hline 21 & Produtos farmacéuticos & $-1,10$ & 28 & Maquinaria & $-1,04$ \\
\hline 13 & Produtos téxtiles & $-1,22$ & 26 & $\begin{array}{l}\text { Produtos informáticos, electrónicos e } \\
\text { ópticos }\end{array}$ & $-1,22$ \\
\hline $29 B$ & $\begin{array}{l}\text { Carrozarías e partes e pezas de vehícu- } \\
\text { los de motor }\end{array}$ & $-1,43$ & 13 & Produtos téxtiles & $-1,27$ \\
\hline $26 B$ & $\begin{array}{l}\text { Outros produtos informáticos, electró- } \\
\text { nicos e ópticos }\end{array}$ & $-1,46$ & $24 B$ & $\begin{array}{l}\text { Outros produtos da metalurxia e pro- } \\
\text { dutos metálicos }\end{array}$ & $-1,68$ \\
\hline 28 & Maquinaria & $-1,62$ & 21 & Produtos farmacéuticos & $-1,89$ \\
\hline $25 B$ & $\begin{array}{l}\text { Outros produtos metálicos; agás ma- } \\
\text { quinaria e equipamento }\end{array}$ & $-2,19$ & $29 B$ & $\begin{array}{l}\text { Carrozarías e partes e pezas de vehícu- } \\
\text { los de motor }\end{array}$ & $-2,53$ \\
\hline 06 & Petróleo cru e gas natural & $-3,75$ & 06 & Petróleo cru e gas natural & $-2,66$ \\
\hline
\end{tabular}

Fonte: elaboración propia a partir de IGE, Marco input-output de Galicia anos 2008 e 2016.

Observando a Táboa 2 e as Táboas A.5, A.6 e A.7 do Anexo no ano 2008, a economía galega presentaba unha vantaxe comparativa en todos os ámbitos xeográficos en que comercia nos Vehículos de motor, na Construción naval, nas Conservas (pescado, moluscos, crustáceos), nas Pezas de roupa e nos produtos da madeira de escasa transformación (taboleiros, palés, etc.). Pola contra, rexistraba desvantaxes comparativas, reveladas globais, nas Producións agrícolas, nos Produtos da industria téxtil e na Fabricación de carrozarías e compoñentes de automóbiles. Este patrón común a todo o comercio galego co exterior sofre dúas alteracións fundamentais no período 2008-2016. En primeiro lugar, a Construción naval retrocede como especialización da economía galega, mantendo o seu papel destacado nos intercambios co resto da UE e do mundo pero vendo reducida a súa importancia na inserción galega no resto do Estado. En segundo lugar, cómpre sinalar a mellora dos valores do IVCR asociados aos produtos agrícolas, resultado que é coherente co avance da rama da Agricultura na estrutura produtiva interior. En contrapartida, vemos incrementada a desvantaxe comparativa nas producións de aceite tanto no eido español como no internacional.

No ámbito español, a economía de Galicia presenta para o ano 2008 vantaxes comparativas específicas no comercio de Enerxía eléctrica, no Leite e produtos gandeiros e na Fabricación de carrozarías e compoñentes de vehículos. Este resultado apunta a que, pese a manter unha forte dependencia respecto do abastecemento internacional destas mercadorías, existen empresas en Galicia capaces de colocar este tipo de produtos no Estado español. Os puntos máis débiles da inserción galega na economía esta- 
tal antes da crise económica atopámolos nos Servizos de publicidade e estudos de mercado e nos Produtos metálicos (agás os empregados na construción). Tras a crise, as maiores vantaxes comparativas da economía galega mantivéronse sen alteracións no ámbito español. No plano das debilidades, observamos un afundimento naquelas ramas que teñen que ver cos servizos máis intensivos en coñecemento, ao verse aumentada a dependencia respecto dos Servizos de programación, consultaría e outros servizos relacionados coa informática; servizos de información.

Nos mercados internacionais, a única produción que presentaba unha vantaxe específica antes da crise económica de 2008 era a da pedra tallada. No tocante ás desvantaxes comparativas reveladas, estas presentan un patrón claramente diferenciado respecto do comercio co Estado español. Por unha banda, vemos unha dependencia respecto de produtos de alta intensidade tecnolóxica (farmacéuticos, informáticos, electrónicos e ópticos). Por outra, Galicia aparece como fortemente dependente no ámbito internacional nas producións de maquinaria, material e equipo eléctrico, etcétera. Destaca tamén aquí o forte déficit que presenta a economía galega no epígrafe de Carrozarías e compoñentes de vehículos de motor, centrado sobre todo no comercio coa UE. Este dato explícase polas compras no exterior de gran parte das pezas dos vehículos que se ensamblan na factoría de PSA-Citröen en Vigo. No comercio co resto do mundo, cómpre subliñar a dependencia que a economía galega presenta en 2008 respecto de insumos enerxéticos tales como o carbón e o petróleo. Como única modificación salientable tras a crise económica, podemos citar a aparición como especialización galega dentro dos mercados internacionais da produción de aluminio. Porén, poderíamos estar ante un mero efecto estatístico, ao se separaren estas producións do groso da metalurxia na táboa de 2016 e non na de 2008.

\section{Recapitulación e discusión dos resultados}

Ao longo dos apartados anteriores comprobamos que a estrutura produtiva interna de Galicia antes da crise económica iniciada no ano 2008 pivotaba arredor dos seguintes catro piares fundamentais: servizos tradicionais, industria de escasa intensidade tecnolóxica, construción e sector público. Os ocos baleiros na estrutura produtiva galega anterior á crise correspondían aos servizos a empresas máis intensivos no emprego de coñecemento, a ramas industriais tecnoloxicamente punteiras e/ou ligadas á fabricación de maquinaria e equipamento, e en menor medida ás producións primarias tanto agrarias como pesqueiras.

A dinámica derivada da crise, reflectida na comparación entre as estruturas económicas dos anos 2008 e 2016, apunta cara a unha continuidade no esquema fundamental de funcionamento da economía galega. Dentro dos seus nodos fundamentais, incorpóranse as ramas primarias, mentres perde importancia a construción naval. Observamos, ademais, como as relacións intersectoriais de Galicia non presentan un reflexo uniforme na inserción exterior dentro dos diferentes ámbitos xeográficos nos que opera. Existe, tanto en 2008 como en 2016, un patrón común de vantaxes e de desvantaxes comparativas da economía galega que convive con patróns específicos de inserción nos ámbitos español e internacional. Destacan, concretamente, as diferenzas existentes, detectadas para o comercio interrexional e internacional, entre as producións nas que a economía galega presenta maior grao de dependencia. No primeiro caso, citamos a necesidade de abastecemento de servizos intensivos en coñecemento. No segundo, os maiores déficits concéntranse no comercio de maquinaria, equipamento e produtos de alta intensidade tecnolóxica. Tal configuración da inserción exterior de Galicia non experimentou variacións de calado tras a crise económica.

Á luz do marco de análise formulado no apartado 2.3 podemos afirmar, en primeiro lugar, que entre os anos 2008 e 2016 a economía galega non levou a cabo un proceso de diversificación tras a crise que lograse ir enchendo os baleiros da súa estrutura económica. De feito, a estrutura económica de Galicia presenta variacións de escaso calado respecto de décadas anteriores, se atendemos aos resultados obtidos por outras investigacións no que se refire aos sectores clave (Fernández Redondo, 2001). Isto resulta lóxico, mais non é necesariamente positivo de cara ao desenvolvemento no medio e longo prazo dunha economía (Hidalgo, Klinger, Barabási e Hausmann, 2007). Como mudanza destacable, a trama 
intersectorial da economía galega incorporou ao seu haber un novo nodo fundamental, coa aparición como sector clave das ramas agrarias, e como sector básico da pesca. 0 rexurdir das ramas primarias como piares da economía galega tras a crise vén a matizar a imaxe secundaria que se lle foi outorgando, progresivamente, no relato sobre a súa estrutura económica, durante as últimas décadas. Desde unha perspectiva cualitativa, as ausencias dentro da estrutura produtiva de Galicia concentrábanse en 2008, e seguían concentrándose en 2016, fundamentalmente nas industrias de maior intensidade tecnolóxica e nos servizos máis intensivos en coñecemento. 0 esquema que describimos tanto para o ano 2008 como para 2016 semella encaixar, en termos europeos, coa descrición das novas formas de dependencia formuladas por Baran e Sweezy, dado o predominio de sectores industriais que, agás no caso da industria do automóbil, poden ser considerados como tecnoloxicamente maduros. Isto podería estar producindo un círculo vicioso no cal a escasa demanda de produtos ou servizos punteiros que se xera en Galicia non é cuberta por subministradores situados no interior do seu espazo económico (Vence Deza e Rodil Marzábal, 2002). Este resultado é coherente, ademais, cos círculos virtuosos observados de maneira análoga noutras economías por Guerrieri e Meliciani (2005).

No plano da inserción exterior, a mellora da posición da nosa balanza comercial non veu da man dunha diversificación substancial da inserción económica galega, polo que as fontes desa mellora entre 2008 e 2016 deberán ser buscadas noutro lugar. Fica acreditado que non se logrou reducir as desvantaxes comparativas da economía galega derivadas da incompletude da súa estrutura produtiva, mantendo e mesmo afondando nos esquemas de dependencia que caracterizan a súa relación co resto do Estado, co resto da UE e co resto do mundo. Resulta evidente que Galicia presenta, antes e despois da crise, dous esquemas de dependencia diferenciados no comercio interrexional e no internacional.

Respecto do resto do Estado, alén das vantaxes comparativas globais do comercio galego, mantéñense certas especializacións produtivas propias do esquema colonial proposto polo propio Beiras Torrado (1981) ou por López Suevos (1980), baseadas nos produtos agrarios e na explotación de recursos naturais (neste caso, fundamentalmente, os ríos para a produción de electricidade). Porén, a economía galega xa non presenta, respecto do resto de España, unha dependencia no abastecemento de produtos industriais de elevada intensidade tecnolóxica. Esta dependencia aparece desprazada cara aos mercados internacionais, nomeadamente o europeo. En relación co resto do Estado si observamos unha nova forma de dependencia non recollida en estudos de épocas anteriores e baseada na importación de servizos a empresas intensivos en coñecemento. Estas ramas produtivas, que operan como "interface" para a incorporación de innovacións nos sistemas produtivos, son xestionadas desde o exterior da economía galega, un resultado coherente cos obtidos noutros estudos máis detallados sobre esta cuestión (Vence Deza e González López, 2009).

Mantendo un esquema que lembra o descrito por Prebisch para as economías subdesenvolvidas, as innovacións entran en Galicia baixo o prisma e os intereses dos espazos económicos centrais do seu ámbito. Redúcense, así, as posibilidades de xerar no seu seo capacidades específicas e dificúltase a adaptación de novos coñecementos ás necesidades do territorio, o cal tamén pode ser entendido como unha forma de "satelización" dunha economía propia do réxime de acumulación pos-fordista. Como consecuencia, as vantaxes da incorporación de empresas galegas ás Cadeas Globais de Valor poderían ser contrarrestadas, dificultando a súa difusión tanto social como territorial (Bair, 2005; Taylor, 2007).

\section{Conclusións}

Na introdución do presente traballo preguntabámonos, en primeiro lugar, acerca de que mudanzas na estrutura económica de Galicia aparecen asociadas á detención do proceso continuado de crecemento económico e de converxencia coa súa contorna anterior á crise económica iniciada en 2008 e á posterior recuperación ata o ano 2016. Á luz dos resultados obtidos, podemos afirmar que a única gran mudanza observada na estrutura intersectorial de Galicia durante este período temporal foi 
a (re)aparición das producións primarias como un dos nodos fundamentais dentro da súa estrutura económica. Tanto as ramas agrarias como a pesca gañan en importancia relativa, recuperando un papel ata certo punto perdido ao longo das últimas décadas. Esta revitalización matiza o seu lugar secundario dentro da economía galega, que poderíamos considerar se tivésemos en conta unicamente o seu peso no PIB e no emprego. 0 reflexo das relacións intersectoriais internas na inserción exterior da economía galega non mudou no fundamental, o que revela, como resultado, a observación de patróns de inserción claramente diferenciados se consideramos o comercio interrexional e mais o internacional de maneira separada. Por tanto, e coa excepción das ramas primarias xa comentada, podemos afirmar que a estrutura económica de Galicia, baseada nos piares da construción, dos servizos de carácter tradicional, da industria de intensidade tecnolóxica media ou baixa e da acción do sector público, non sufriu alteracións de importancia. Os factores que explican o crecemento económico tras a crise e a mellora do saldo na balanza comercial de Galicia deben ser buscados noutro lugar.

En segundo lugar, neste artigo procuramos determinar en que medida a evolución da estrutura económica de Galicia entre os anos 2008 e 2016 podía ser identificada cunha dinámica de desenvolvemento rexional, entendendo como tal o avance cara a unha trama intersectorial máis completa e cun maior número de sectores clave ou fundamentais. Respecto do primeiro criterio adoptado, podemos ratificar a persistencia de importantes baleiros dentro da estrutura produtiva interna de Galicia, que teñen loxicamente o seu reflexo na súa inserción exterior. Se ben cuantitativamente detectamos que existen menos ramas consideradas como sectores independentes, coa conseguinte redución do seu peso na produción interior e no emprego, cómpre destacar entre os baleiros que persisten tras a crise económica os sectores industriais tecnoloxicamente máis dinámicos e os servizos a empresas máis intensivos en coñecemento. Esta situación leva a que a economía galega dependa en ambos os anos observados dos mercados internacionais, nomeadamente o europeo, para a subministración de produtos de alta intensidade tecnolóxica, maquinaria e equipamento, e do resto Estado español para se abastecer de gran parte dos servizos a empresas máis punteiros.

Respecto do segundo criterio de análise, comprobamos como a inclusión de novas ramas entre os sectores clave da economía galega en 2016 foi protagonizada por ramas altamente relacionadas cos catro piares diferenciados á hora de describir os nodos das relacións intersectoriais no ano 2008. Non podemos, á luz da metodoloxía empregada, constatar a aparición de novos polos dentro da estrutura económica de Galicia que expliquen a evolución do seu PIB e do saldo da balanza comercial. Esta conclusión non pode ser formulada categoricamente con base nas operacións realizadas nesta investigación. Porén, os resultados obtidos referidos á inserción exterior semellan confirmala, ao non detectar a aparición de novas vantaxes comparativas reveladas na economía galega nos ámbitos español, europeo ou mundial.

Para finalizar, podemos sinalar, desde unha perspectiva máis cualitativa, que a incompletude da estrutura económica de Galicia, unida ao dominio nela de sectores tradicionais e/ou asociados a tecnoloxías maduras, reducen as súas posibilidades para ancorar a actividade económica máis alá dos ciclos de bonanza ou recesión. A estrutura produtiva de Galicia nos anos 2008 e 2016, conforme os resultados obtidos, pivotaba arredor dun reducido número de nodos, con pouca marxe para a creación de capacidades específicas no territorio, e extremadamente dependentes de decisións estratéxicas das grandes empresas e/ou do sector público. Tal configuración pode constituír, en momentos de recesión, un incentivo para o establecemento dun determinado modelo de competitividade dentro do territorio baseado na redución de custos laborais, na subvención no prezo a determinadas subministracións ou en maiores facilidades á hora de explotar os recursos naturais. Os datos achegados relativos ao contexto macroeconómico poderían estar apuntando nesa dirección, ao sinalar que a recuperación económica non veu acompañada dun relanzamento do proceso de converxencia en renda per cápita cos niveis español e europeo, tal e como sucedía no período de crecemento anterior á crise. En calquera caso, esta última conclusión ten un carácter absolutamente preliminar. Un estudo máis detallado nesta dirección excede, con moito, o propósito da presente investigación. 


\section{Anexo}

Nas Táboas A.1 a A.4 preséntanse os sectores claves (Táboa A.1), básicos (Táboa A.2), motores (Táboa A.3) e independentes (Táboa A.4) na economía galega para os anos 2008 e 2016.

A continuación, nas Táboas A.5 a A.7 recóllense as produción con maiores e menores índices de vantaxe comparativa revelada no comercio galego co resto do Estado español (Táboa A.5), da Unión Europea (Táboa A.6) e do mundo (Táboa A.7).

Táboa A.1. Sectores claves na economía galega. Anos 2008 e 2016

\begin{tabular}{l}
2008 \\
\hline Actividades inmobiliarias. \\
$\begin{array}{l}\text { Actividades sanitarias e de servizos sociais de non } \\
\text { mercado. }\end{array}$ \\
$\begin{array}{l}\text { Administración pública e defensa; Seguridade Social } \\
\text { obrigatoria. }\end{array}$
\end{tabular}

Comercio polo miúdo, salvo de vehículos de motor e motocicletas.

Comercio por xunto e intermediarios do comercio, agás de vehículos de motor.

\section{Construción.}

Coquerías e refino de petróleo.

Fabricación de vehículos de motor, remolques e semirremolques.

Fornecemento de enerxía eléctrica, gas, vapor e aire acondicionado.

Metalurxia; fabricación de produtos de ferro, aceiro e ferroaliaxes.

Servizos de comidas e bebidas.

\section{6}

Actividades inmobiliarias.

Actividades sanitarias e de servizos sociais de mercado.

Actividades sanitarias e de servizos sociais de non mercado.

Administración pública e defensa; Seguridade Social obrigatoria.

Agricultura, gandaría, caza e servizos relacionados con elas.

Comercio polo miúdo, salvo de vehículos de motor e motocicletas.

Comercio por xunto e intermediarios do comercio, agás de vehículos de motor.

\section{Construción.}

Educación de non mercado.

Fabricación de produtos metálicos, agás maquinaria e equipamento.

Fabricación de vehículos de motor, remolques e semirremolques.

Fornecemento de enerxía eléctrica, gas, vapor e aire acondicionado.

Procesamento e conservación de peixes, crustáceos e moluscos.

Servizos de comidas e bebidas.

Transporte terrestre e por tubaxe. 
Táboa A.2. Sectores básicos da economía galega. Anos 2008 e 2016

\begin{tabular}{l}
2008 \\
\hline Actividades de alugueiro. \\
Actividades de seguridade e investigación; servizos a \\
edificios e actividades de xardinería; actividades ad- \\
ministrativas de oficina e outras actividades auxiliares \\
das empresas.
\end{tabular}

Actividades postais e de correo.

Actividades relacionadas co emprego.

Actividades xurídicas e de contabilidade; actividades das sedes centrais; actividades de consultaría e de xestión empresarial.

Almacenamento e actividades anexas ao transporte.

Fabricación de bebidas e industria do tabaco.

Fabricación de produtos de caucho e plásticos.

Fabricación de produtos metálicos, agás maquinaria e equipamento.

Fabricación doutros produtos minerais non metálicos. Industrias extractivas.

Outras actividades profesionais, científicas, técnicas e veterinarias de mercado.

Publicidade e estudos de mercado.

Reparación e instalación de maquinaria e equipamento.

Servizos financeiros, agás seguros e fondos de pensións.

Servizos técnicos de arquitectura e enxeñaría; ensaios e análise técnica.

Telecomunicacións.

Transporte terrestre e por tubaxe.

\section{6}

Actividades auxiliares aos servizos financeiros e aos seguros.

Actividades de alugueiro.

Actividades de seguridade e investigación; servizos a edificios e actividades de xardinería; actividades administrativas de oficina e outras actividades auxiliares das empresas.

Actividades postais e de correo.

Actividades relacionadas co emprego.

Actividades xurídicas e de contabilidade; actividades das sedes centrais; actividades de consultaría e de xestión empresarial.

Almacenamento e actividades anexas ao transporte.

Coquerías e refino de petróleo.

Fabricación de bebidas e industria do tabaco.

Fabricación de produtos de caucho e plásticos.

Fabricación de produtos para a alimentación animal.

Fabricación doutros produtos minerais non metálicos.

Industrias extractivas.

Outras actividades profesionais, científicas, técnicas e veterinarias.

Pesca.

Publicidade e estudos de mercado.

Reparación e instalación de maquinaria e equipamento.

Servizos financeiros, agás seguros e fondos de pensións.

Telecomunicacións. 
Táboa A.3. Sectores motores da economía galega. Anos 2008 e 2016

\begin{tabular}{ll}
\hline 2008 & 2016 \\
\hline $\begin{array}{l}\text { Actividades de saneamento e xestión de residuos de } \\
\text { non mercado. }\end{array}$ & $\begin{array}{l}\text { Actividades artísticas, recreativas e de entretemento } \\
\text { de mercado. }\end{array}$ \\
$\begin{array}{l}\text { Actividades sanitarias e de servizos sociais de merca- } \\
\text { do. }\end{array}$ & $\begin{array}{l}\text { Actividades de saneamento e xestión de residuos de } \\
\text { non mercado. }\end{array}$ \\
$\begin{array}{l}\text { Confección de roupa de vestir e industria do coiro e do } \\
\text { calzado. }\end{array}$ & $\begin{array}{l}\text { Confección de roupa de vestir e industria do coiro e do } \\
\text { calzado. }\end{array}$ \\
$\begin{array}{l}\text { Educación de non mercado. } \\
\text { Fabricación de produtos lácteos. }\end{array}$ & $\begin{array}{l}\text { Fabricación de produtos lácteos. } \\
\text { Industria da madeira e da cortiza, agás mobles; cesta- } \\
\text { ría e espartaría. }\end{array}$ \\
$\begin{array}{ll}\text { Fabricación doutro material de transporte. } \\
\text { Procesamento e conservación de carne e elaboración } \\
\text { de produtos cárnicos. }\end{array}$ & $\begin{array}{l}\text { Procesamento e conservación de carne e elaboración } \\
\text { de produtos cárnicos. }\end{array}$ \\
$\begin{array}{l}\text { Procesamento e conservación de peixes, crustáceos e } \\
\text { moluscos. }\end{array}$ & $\begin{array}{l}\text { Subministración de auga, actividades de saneamento, } \\
\text { xestión de residuos e descontaminación de mercado. }\end{array}$ \\
\hline
\end{tabular}

Fonte: elaboración propia a partir de IGE, Marco input-output de Galicia anos 2008 e 2016.

Táboa A.4. Sectores independentes da economía galega. Anos 2008 e 2016

$2008 \quad 2016$

Actividades artísticas, recreativas e de entretemento de mercado.

Actividades artísticas, recreativas e de entretemento de non mercado.

Actividades asociativas.

Actividades auxiliares aos servizos financeiros e aos seguros.

Actividades cinematográficas de vídeo e televisión, gravación de son e edición musical; actividades de programación e emisión de radio e televisión.

Actividades das axencias de viaxes, operadores turísti- Acuicultura. cos, servizos de reservas e actividades relacionadas.

Actividades dos fogares como empregadores de persoal doméstico.

Acuicultura.

Agricultura, gandaría, caza e servizos relacionados con Educación de mercado.

Actividades artísticas, recreativas e de entretemento de non mercado.

Actividades asociativas.

Actividades cinematográficas de vídeo e televisión, gravación de son e edición musical; actividades de programación e emisión de radio e televisión.

Actividades das axencias de viaxes, operadores turísticos, servizos de reservas e actividades relacionadas.

Actividades dos fogares como empregadores de persoal doméstico.

Artes gráficas e reprodución de soportes gravados.

\section{Edición.}

elas. 
Táboa A.4 (continuación). Sectores independentes da economía galega. Anos 2008 e 2016

\begin{tabular}{l}
\hline 2008 \\
\hline Artes gráficas e reprodución de soportes gravados. \\
Edición. \\
Educación de mercado. \\
Fabricación de maquinaria e equipamento n.c.n. \\
Fabricación de material e equipamento eléctrico. \\
Fabricación de mobles. \\
Fabricación de produtos informáticos, electrónicos e \\
ópticos.
\end{tabular}

Fabricación de produtos para a alimentación animal. Industria da madeira e da cortiza, agás mobles; cestaría e espartaría.

Industria do papel.

Industria química e fabricación de produtos farmacéuticos.

Industria téxtil.

Investigación e desenvolvemento.

Outras industrias alimentarias.

Outras industrias manufactureiras.

Outros servizos persoais.

Pesca.

Programación, consultaría e outras actividades relacionadas coa informática; servizos de información.

Reparación de ordenadores, efectos persoais e artigos de uso doméstico.

Seguros, reaseguros e fondos de pensións agás Seguridade Social obrigatoria.

Servizos de aloxamento.

Silvicultura e explotación forestal.

Subministración de auga, actividades de saneamento, xestión de residuos e descontaminación de mercado.

Transporte marítimo e por vías navegables interiores; transporte aéreo.

Venda e reparación de vehículos de motor.

\section{6}

Fabricación de maquinaria e equipamento n.c.n.

Fabricación de material e equipamento eléctrico.

Fabricación de mobles.

Fabricación de produtos informáticos, electrónicos e ópticos.

Fabricación doutro material de transporte.

Industria do papel.

Industria química e fabricación de produtos farmacéuticos.

Industria téxtil.

Investigación e desenvolvemento.

Outras industrias alimentarias.

Outras industrias manufactureiras.

Outros servizos persoais.

Programación, consultaría e outras actividades relacionadas coa informática; servizos de información.

Reparación de ordenadores, efectos persoais e artigos de uso doméstico.

Seguros, reaseguros e fondos de pensións agás Seguridade Social obrigatoria.

Servizos de aloxamento.

Servizos técnicos de arquitectura e enxeñería; ensaios e análise técnica.

Silvicultura e explotación forestal.

Transporte marítimo e por vías navegables interiores; transporte aéreo.

Venda e reparación de vehículos de motor.

Fonte: elaboración propia a partir de IGE, Marco input-output de Galicia anos 2008 e 2016. 
Táboa A.5. Producións con maiores e menores índices de vantaxe comparativa revelada no comercio galego co resto do Estado español

\begin{tabular}{|c|c|c|c|c|c|}
\hline \multicolumn{6}{|c|}{ Maiores índices } \\
\hline Código & Produto & 2008 & Código & Produto & 2016 \\
\hline 10B2 & $\begin{array}{l}\text { Conservas (pescado, moluscos e crustá- } \\
\text { ceos). }\end{array}$ & 2,95 & 10B2 & $\begin{array}{l}\text { Conservas (pescado, moluscos e crustá- } \\
\text { ceos). }\end{array}$ & 6,17 \\
\hline $35 \mathrm{~A}$ & $\begin{array}{l}\text { Servizos de produción, transporte e dis- } \\
\text { tribución de enerxía eléctrica. }\end{array}$ & 2,83 & $35 \mathrm{~A}$ & $\begin{array}{l}\text { Servizos de produción, transporte e dis- } \\
\text { tribución de enerxía eléctrica. }\end{array}$ & 4,54 \\
\hline 14 & Pezas de roupa. & 2,50 & 01B & Produtos gandeiros. & 2,41 \\
\hline $29 \mathrm{~A}$ & Vehículos de motor. & 2,45 & 46 & $\begin{array}{l}\text { Servizos de comercio por xunto e in- } \\
\text { termediarios, agás de vehículos de mo- } \\
\text { tor. }\end{array}$ & 2,36 \\
\hline $29 \mathrm{~B}$ & $\begin{array}{l}\text { Carrozarías e partes e pezas de vehícu- } \\
\text { los de motor. }\end{array}$ & 1,95 & 29B & $\begin{array}{l}\text { Carrozarías e partes e pezas de vehícu- } \\
\text { los de motor. }\end{array}$ & 1,71 \\
\hline $30 \mathrm{~A}$ & Construción naval. & 1,82 & $29 \mathrm{~A}$ & Vehículos de motor. & 1,45 \\
\hline 46 & $\begin{array}{l}\text { Servizos de comercio por xunto e in- } \\
\text { termediarios, agás de vehículos de mo- } \\
\text { tor. }\end{array}$ & 1,54 & 52 & Servizos anexos ao transporte. & 1,43 \\
\hline $10 \mathrm{C} 1$ & Leite de consumo líquido e en po. & 1,52 & 16B & Outros produtos de madeira. & 1,25 \\
\hline 01B & Produtos gandeiros. & 1,38 & $10 \mathrm{C} 1$ & Leite de consumo líquido e en po. & 1,25 \\
\hline $16 \mathrm{~B}$ & Outros produtos de madeira. & 1,24 & 14 & Pezas de roupa. & 1,17 \\
\hline \multicolumn{6}{|c|}{ Menores índices } \\
\hline Código & Produto & 2008 & Código & Produto & 2016 \\
\hline 22 & Produtos de caucho e plástico. & $-0,94$ & $10 \mathrm{E} 2$ & Aceites e graxas vexetais e animais. & $-0,97$ \\
\hline $10 \mathrm{~A} 2$ & Produtos cárnicos. & $-0,95$ & 51 & Transporte aéreo. & $-0,97$ \\
\hline $01 \mathrm{~A}$ & Produtos agrícolas. & $-1,03$ & 25 & $\begin{array}{l}\text { Produtos metálicos, agás maquinaria e } \\
\text { equipamento. }\end{array}$ & $-1,14$ \\
\hline 64 & $\begin{array}{l}\text { Servizos financeiros, agás seguros e } \\
\text { fondos de pensións. }\end{array}$ & $-1,08$ & 13 & Produtos téxtiles. & $-1,37$ \\
\hline $62 \_63$ & $\begin{array}{l}\text { Servizos de programación, consultaría e } \\
\text { outros servizos relacionados coa in- } \\
\text { formática; servizos de información. }\end{array}$ & $-1,21$ & $62 \_63$ & $\begin{array}{l}\text { Servizos de programación, consultaría } \\
\text { e outros servizos relacionados coa in- } \\
\text { formática; servizos de información. }\end{array}$ & $-1,43$ \\
\hline $20 \mathrm{~B}$ & Outros produtos químicos. & $-1,38$ & 19 & Refino de petróleo. & $-1,61$ \\
\hline 13 & Produtos téxtiles. & $-1,62$ & 20B & Outros produtos químicos. & $-1,94$ \\
\hline 73 & $\begin{array}{l}\text { Servizos de publicidade e estudos de } \\
\text { mercado. }\end{array}$ & $-1,81$ & 73 & $\begin{array}{l}\text { Servizos de publicidade e estudos de } \\
\text { mercado. }\end{array}$ & $-1,98$ \\
\hline $10 \mathrm{E} 4$ & Outros produtos alimenticios. & $-1,86$ & $10 \mathrm{E} 4$ & Outros produtos alimenticios. & $-1,99$ \\
\hline $25 \mathrm{~B}$ & $\begin{array}{l}\text { Outros produtos metálicos; agás ma- } \\
\text { quinaria e equipamento. }\end{array}$ & $-4,06$ & 24B & $\begin{array}{l}\text { Outros produtos da metalurxia e pro- } \\
\text { dutos metálicos. }\end{array}$ & $-2,81$ \\
\hline
\end{tabular}

Fonte: elaboración propia a partir de IGE, Marco input-output de Galicia anos 2008 e 2016. 
Táboa A.6. Producións con maiores e menores índices de vantaxe comparativa revelada no comercio galego coa Unión Europea

\begin{tabular}{|c|c|c|c|c|c|}
\hline \multicolumn{6}{|c|}{ Maiores índices } \\
\hline Código & Produto & 2008 & Código & Produto & 2016 \\
\hline $29 \mathrm{~A}$ & Vehículos de motor. & 15,27 & $29 \mathrm{~A}$ & Vehículos de motor. & 12,76 \\
\hline 46 & $\begin{array}{l}\text { Servizos de comercio por xunto e in- } \\
\text { termediarios, agás de vehículos de } \\
\text { motor. }\end{array}$ & 2,26 & 46 & $\begin{array}{l}\text { Servizos de comercio por xunto e in- } \\
\text { termediarios, agás de vehículos de } \\
\text { motor. }\end{array}$ & 2,86 \\
\hline 14 & Pezas de roupa. & 1,60 & 10B2 & $\begin{array}{l}\text { Conservas (pescado, moluscos e } \\
\text { crustáceos). }\end{array}$ & 2,44 \\
\hline 10B2 & $\begin{array}{l}\text { Conservas (pescado, moluscos e } \\
\text { crustáceos). }\end{array}$ & 1,56 & $24 \mathrm{~A}$ & $\begin{array}{l}\text { Aluminio, outros produtos metais } \\
\text { non férreos e metais preciosos. }\end{array}$ & 1,94 \\
\hline $30 \mathrm{~A}$ & Construción naval. & 1,05 & $47 \mathrm{~A}$ & $\begin{array}{l}\text { Servizos de comercio polo miúdo } \\
\text { agás de vehículos de motor e de } \\
\text { combustible para vehículos de mo- } \\
\text { tor. }\end{array}$ & 1,64 \\
\hline 23D & $\begin{array}{l}\text { Pedra tallada, labrada e acabada, } \\
\text { manufacturas de pedra. }\end{array}$ & 0,96 & 19 & Refino de petróleo. & 1,20 \\
\hline $17 \mathrm{~A}$ & Pasta de papel, papel e cartón. & 0,70 & 14 & Pezas de roupa. & 0,98 \\
\hline 16B & Outros produtos de madeira. & 0,54 & $23 \mathrm{C}$ & $\begin{array}{l}\text { Pedra tallada, labrada e acabada, } \\
\text { manufacturas de pedra. }\end{array}$ & 0,96 \\
\hline $10 \mathrm{~A} 1$ & Carne elaborada e en conserva. & 0,49 & 25 & $\begin{array}{l}\text { Produtos metálicos, agás maquinaria } \\
\text { e equipamento. }\end{array}$ & 0,78 \\
\hline 52 & Servizos anexos ao transporte. & 0,30 & $16 \mathrm{~B}$ & Outros produtos de madeira. & 0,73 \\
\hline \multicolumn{6}{|c|}{ Menores índices } \\
\hline Código & Produto & 2008 & Código & Produto & 2016 \\
\hline $26 \mathrm{~A}$ & Ordenadores e equipos periféricos. & $-0,70$ & $01 \mathrm{~A}$ & Produtos agrícolas. & $-0,77$ \\
\hline 32 & Outros artigos manufacturados. & $-0,72$ & 22 & Produtos de caucho e plástico. & $-0,97$ \\
\hline 13 & Produtos téxtiles. & $-0,80$ & 32 & Outros artigos manufacturados. & $-0,98$ \\
\hline 37_39M & $\begin{array}{l}\text { Servizos de rede de sumidoiros, xes- } \\
\text { tión de residuos e saneamento de } \\
\text { mercado. }\end{array}$ & $-0,80$ & 13 & Produtos téxtiles. & $-1,04$ \\
\hline 27 & Material e equipo eléctrico. & $-1,65$ & $24 \mathrm{~B}$ & $\begin{array}{l}\text { Outros produtos da metalurxia e } \\
\text { produtos metálicos. }\end{array}$ & $-1,23$ \\
\hline 24 & $\begin{array}{l}\text { Produtos de metalurxia e produtos } \\
\text { metálicos. }\end{array}$ & $-1,88$ & 27 & Material e equipo eléctrico. & $-1,59$ \\
\hline 21 & Produtos farmacéuticos. & $-2,05$ & 26 & $\begin{array}{l}\text { Produtos informáticos, electrónicos e } \\
\text { ópticos. }\end{array}$ & $-1,84$ \\
\hline $26 B$ & $\begin{array}{l}\text { Outros produtos informáticos, elec- } \\
\text { trónicos e ópticos. }\end{array}$ & $-2,30$ & 21 & Produtos farmacéuticos. & $-2,30$ \\
\hline 28 & Maquinaria. & $-3,52$ & 28 & Maquinaria. & $-2,44$ \\
\hline $29 B$ & $\begin{array}{l}\text { Carrozarías e partes e pezas de ve- } \\
\text { hículos de motor. }\end{array}$ & $-7,65$ & $29 B$ & $\begin{array}{l}\text { Carrozarías e partes e pezas de vehí- } \\
\text { culos de motor. }\end{array}$ & $-8,05$ \\
\hline
\end{tabular}

Fonte: elaboración propia a partir de IGE, Marco input-output de Galicia anos 2008 e 2016. 
Táboa A.7. Producións con maiores e menores índices de vantaxe comparativa revelada no comercio galego co resto do mundo

\begin{tabular}{|c|c|c|c|c|c|}
\hline \multicolumn{6}{|c|}{ Maiores índices } \\
\hline Código & Produto & 2008 & Código & Produto & 2016 \\
\hline $30 \mathrm{~A}$ & Construción naval. & 5,09 & $29 \mathrm{~A}$ & Vehículos de motor. & 6,20 \\
\hline $29 \mathrm{~A}$ & Vehículos de motor. & 3,71 & $30 \mathrm{~A}$ & Construción naval. & 3,54 \\
\hline 46 & $\begin{array}{l}\text { Servizos de comercio por xunto e in- } \\
\text { termediarios, agás de vehículos de } \\
\text { motor. }\end{array}$ & 1,30 & 46 & $\begin{array}{l}\text { Servizos de comercio por xunto e in- } \\
\text { termediarios, agás de vehículos de } \\
\text { motor. }\end{array}$ & 2,55 \\
\hline $29 B$ & $\begin{array}{l}\text { Carrozarías e partes e pezas de } \\
\text { vehículos de motor. }\end{array}$ & 0,81 & 19 & Refino de petróleo. & 1,60 \\
\hline 27 & Material e equipo eléctrico. & 0,73 & 25 & $\begin{array}{l}\text { Produtos metálicos, agás maquinaria } \\
\text { e equipamento. }\end{array}$ & 1,46 \\
\hline $16 \mathrm{~B}$ & Outros produtos de madeira. & 0,25 & 14 & Pezas de roupa. & 1,01 \\
\hline $23 \mathrm{D}$ & $\begin{array}{l}\text { Pedra tallada, labrada e acabada, ma- } \\
\text { nufacturas de pedra. }\end{array}$ & 0,23 & 52 & Servizos anexos ao transporte. & 1,01 \\
\hline 52 & Servizos anexos ao transporte. & 0,17 & $16 \mathrm{~B}$ & Outros produtos de madeira. & 0,81 \\
\hline 49B2 & $\begin{array}{l}\text { Transporte por estrada de mercadorí- } \\
\text { as, mudanzas e transporte por tubaxe }\end{array}$ & 0,13 & $23 \mathrm{C}$ & $\begin{array}{l}\text { Pedra tallada, labrada e acabada, ma- } \\
\text { nufacturas de pedra. }\end{array}$ & 0,66 \\
\hline $10 \mathrm{~A} 1$ & Carne elaborada e en conserva. & 0,12 & 31 & Mobles. & 0,59 \\
\hline \multicolumn{6}{|c|}{ Menores índices } \\
\hline Código & Produto & 2008 & Código & Produto & 2016 \\
\hline 32 & Outros artigos manufacturados. & $-1,36$ & 32 & Outros artigos manufacturados. & $-1,28$ \\
\hline 28 & Maquinaria. & $-1,49$ & $29 B$ & $\begin{array}{l}\text { Carrozarías e partes e pezas de } \\
\text { vehículos de motor. }\end{array}$ & $-1,36$ \\
\hline $01 \mathrm{~A}$ & Produtos agrícolas. & $-1,67$ & 07 & Minerais metálicos. & $-1,43$ \\
\hline 21 & Produtos farmacéuticos. & $-1,92$ & 13 & Produtos téxtiles. & $-1,51$ \\
\hline 05 & Hulla, antracita e lignito. & $-1,93$ & 05 & Hulla, antracita e lignito. & $-2,04$ \\
\hline 07 & Minerais metálicos. & $-1,98$ & $10 \mathrm{E} 2$ & Aceites e graxas vexetais e animais & $-2,20$ \\
\hline 14 & Pezas de roupa. & $-3,78$ & 26 & $\begin{array}{l}\text { Produtos informáticos, electrónicos e } \\
\text { ópticos. }\end{array}$ & $-2,88$ \\
\hline 10B1 & $\begin{array}{l}\text { Conxelados (pescado, moluscos e } \\
\text { crustáceos). }\end{array}$ & $-4,45$ & 21 & Produtos farmacéuticos. & $-4,60$ \\
\hline $26 B$ & $\begin{array}{l}\text { Outros produtos informáticos, elec- } \\
\text { trónicos e ópticos. }\end{array}$ & $-4,82$ & 10B1 & $\begin{array}{l}\text { Conxelados (pescado, moluscos e } \\
\text { crustáceos). }\end{array}$ & $-5,90$ \\
\hline 06 & Petróleo cru e gas natural. & $-21,89$ & 06 & Petróleo cru e gas natural. & $-13,27$ \\
\hline
\end{tabular}

Fonte: elaboración propia a partir de IGE, Marco input-output de Galicia anos 2008 e 2016. 


\section{Bibliografía}

Alves Cêpeda, V. (2005). Celso Furtado e a interpretação do subdesenvolvimento. Perspectivas: Revista de Ciências Sociais, 28(1), 57-77. Recuperado de: https://periodicos.fclar.unesp.br/perspectivas/article/view/11

Bachelard, G. (1974). La formación del espíritu científico: contribución a un psicoanálisis del conocimiento objetivo. Buenos Aires, Argentina: Siglo veintiuno Argentina.

Bair, J. (2005). From commodity chains to value chains and back again? New Haven, CT: Yale University.

Beiras Torrado, X. M. (1981). O atraso económico de Galicia. (2ª ed.). Vigo: Galaxia.

Caballero Álvarez, A. (1978). Los sectores clave del crecimiento económico: el caso de Galicia. Boletín de Estudios Económicos, 33(105), 45-83.

Couto, J. M. (2007). O pensamento desenvolvimentista de Raúl Prebisch. Economia e Sociedade, 16(1), 45-64. DOI: https://doi.org/10.1590/s0104-06182007000100003

del Castillo Cuervo-Arango, F. (1988). La evolución del análisis input-output regional y la experiencia española. Ekonomiaz. Revista Vasca de Economía, 11, 105-140.

Recuperado de: https://dialnet.unirioja.es/servlet/articulo?codigo $=273370$

Dietzenbacher, E. (1997). In vindication of the Ghosh model: A reinterpretation as a price model. Journal of Regional Science, 37(4), 629-651. DOI: https://doi.org/10.1111/0022-4146.00073

Eurostat Database. (2019). Gross domestic product (GDP) at current market prices by NUTS 2 regions. Luxembourg, Luxembourg: Eurostat.

Recuperado de: https://appsso.eurostat.ec.europa.eu/nui/show.do?dataset=nama 10r 2gdp\&lang=en

Felipe, J., Kumar, U., Abdon, A., e Bacate, M. (2012). Product complexity and economic development. Structural Change and Economic Dynamics, 23(1), 36-68. DOI: https://doi.org/10.1016/i.strueco.2011.08.003

Fernández Fernández, M., e Fernández Grela, M. (2003). La estructura productiva de la economía gallega. Santiago de Compostela: Centro de Investigación Económica y Financiera. Fundación Caixa Galicia.

Fernández Redondo, M. (2001). Política regional e interdependencia sectorial de la economía de Galicia: un análisis a traves de tablas input-output. (Tese de doutoramento). A Coruña: Universidade da Coruña. Recuperado de:

https://ruc.udc.es/dspace/bitstream/handle/2183/1203/FernandezRedondo_Marta TD 2001.pdf?sequence =1\&isAllowed=y

Foster-Carter, A. (1976). From Rostow to Gunder Frank: Conflicting paradigms in the analysis of underdevelopment. World Development, 4(3), 167-180. DOI: https://doi.org/10.1016/0305-750X(76)90025-5

Frank, A. G. (1966). The development of underdevelopment. Monthy Review, 18(4), 17-31.

Gala, P., Camargo, J., Magacho, G., e Rocha, I. (2018). Sophisticated jobs matter for economic complexity: An empirical analysis based on input-output matrices and employment data. Structural Change and Economic Dynamics, 45, 1-8. DOI: https://doi.org/10.1016/i.strueco.2017.11.005

Ghosh, A. (1958). Input-Output approach in an allocation system. Economica, 25(97), 58-64. DOI: https://doi.org/10.2307/2550694

Guerrieri, P., e Meliciani, V. (2005). Technology and international competitiveness: The interdependence between manufacturing and producer services. Structural Change and Economic Dynamics, 16(4), 489-502. DOI: https://doi.org/10.1016/j.strueco.2005.02.002

Guilhoto, J. (2001). Leontief e insumo-produto: antecedentes, princípios e evolução. Revista de Economia e Sociologia Rural, 47(2), 1-43. Recuperado de: https://mpra.ub.uni-muenchen.de/id/eprint/54649

Gurrieri, A. (1983). Technical progress and its fruits: The idea of development in the works of Raul Prebisch. Journal of Economic Issues, 17(2), 389-396. DOI: https://doi.org/10.1080/00213624.1983.11504122

Hidalgo, C. A., Klinger, B., Barabási, A.-L., e Hausmann, R. (2007). The product space conditions the development of nations. Science, 317(5837), 482-487. DOI: https://doi.org/10.1126/science.1144581

Instituto Galego de Estatística. (2010). A economía galega a través do marco input-output de Galicia, 2005. Santiago de Compostela: Xunta de Galicia. Consellería de Facenda.

Recuperado de: https://www.ige.eu/estatico/pdfs/s3/publicaciones/Imput output05.pdf

Instituto Galego de Estatística. (2019). Contas económicas de Galicia. Revisión Estatística 2019. Recuperado de: https://www.ige.eu/web/mostrar_actividade_estatistica.jsp?idioma=gl\&codigo=0307007001

Instituto Galego de Estatística. (2008). Marco input-output de Galicia 2008. Recuperado de: https://www.ige.eu/web/mostrar actividade estatistica.jsp?idioma=gl\&codigo=0307007003

Instituto Galego de Estatística. (2016). Marco input-output de Galicia 2016. Recuperado de: https://www.ige.eu/web/mostrar_actividade estatistica.jsp?idioma=gl\&codigo=0307007003 
Instituto Nacional de Estadística. (2020). Contabilidad Regional de España. Recuperado de: https://www.ine.es/dyngs/INEbase/es/operacion.htm?c=Estadistica C\&cid=1254736167628\&menu=result ados\&idp=1254735576581\#!tabs-1254736158133

Katz, C. (2016). Centro y periferia en el marxismo de posguerra. El Ágora USB. Revista de Ciencias Sociales, 16(2), 623-642. DOI: https://doi.org/10.21500/16578031.2538

Kleiman, E. (1970). Tastes, trade, and the comparison of structural interdependence. Quarterly Journal of Economics, 84(2), 279-287. DOI: https://doi.org/10.2307/1883014

Kohli, M. C. (2001). Leontief and the U.S. bureau of labor statistics, 1941-54: Developing a framework for measurement. History of Political Economy, 33(5), 190-212. DOI: https://doi.org/10.1215/00182702-33-suppl 1-190

Kuhn, T. S. (1984). La estructura de las revoluciones científicas. Madrid: Fondo de Cultura Económica.

Leontief, W. (1936). Quantitative input and output relations in the economic systems of the United States. The Review of Economics and Statistics, 18(3), 105. DOI: https://doi.org/10.2307/1927837

Leontief, W. (1944). Output, employment, consumption, and investment. The Quarterly Journal of Economics, 58(2), 290-314. DOI: https://doi.org/10.2307/1883321

Leontief, W. (1963). The structure of development. Scientific American, 209(3), 148-166.

Leontief, W. (1967). An alternative to aggregation in input-output analysis and national accounts. The Review of Economics and Statistics, 49(3), 412-419. DOI: https://doi.org/https://doi.org/10.2307/1926651

Leontief, W. (1991). The economy as a circular flow. Structural Change and Economic Dynamics, 2(1), 181-212. DOI: https://doi.org/10.1016/0954-349X(91)90012-H

López Hernández, I., e Rodríguez López, E. (2010). Fin de ciclo. Financiarización, territorio y sociedad de propietarios en la onda larga del capitalismo hispano (1959-2010). Madrid: Traficantes de Sueños.

López-Suevos, R. (1980). Do capitalismo colonial. Santiago de Compostela: Edicións do Cerne.

McGregor, P. G., Swales, J. K., e Ping Yin, Y. (1996). A long-run interpretation of regional input-output analysis. Journal of Regional Science, 36(3), 479-501. DOI: https://doi.org/https://doi.org/10.1111/i.1467-9787.1996.tb01113.x

McKenzie, L. (1957). An elementary analysis of the Leontief system. Econometrica, 25(3), 456-462. DOI: https://doi.org/10.2307/1907961

Miller, R. E., e Blair, P. D. (2009). Input-Output analysis. Foundations and Extensions. (2 ${ }^{\underline{a}}$ ed.). Cambridge, UK: Cambridge University Press.

Moses, L. N. (1974). Outputs and prices in interindustry models. Papers of the Regional Science Association, 32(1), 6-18. DOI: https://doi.org/10.1007/BF01942286

Muñoz Cidad, C. (2000). Modelo de demanda. En C. Muñoz Cidad, Las cuentas de la nación. Introducción a la Economía Aplicada (pp. 201-240). Madrid: Civitas.

Outes Ruso, X. L. (2012). O colapso do capitalismo español: leccións e preguntas para despois dunha crise. Revista Galega de Economía, 21(Extraordinario), 91-118. Recuperado de: https://revistas.usc.es/index.php/rge/article/view/424

Prado, C. (2003). Método de deflación de variables económicas: cuentas económicas y tablas input-output. Vitoria-Gasteiz: Euskal Estatistika Erakundea.

Prebisch, R. (1983). Cinco etapas de mi pensamiento sobre el desarrollo económico. El Trimestre Económico, 50(198), 1077-1096. Recuperado de: https://www.jstor.org/stable/23395714

Rasmussen, P. (1956). Studies in inter sectoral relations. Amsterdam, Netherlands: North Holland.

Rose, A., e Miernyk, W. (1989). Input-Output analysis: The first fifty years. Economic Systems Research, 1(2), 229-272. DOI: https://doi.org/10.1080/09535318900000016

Rostow, W. W. (1956). The take-off into self-sustained growth. The Economic Journal, 66(261), 25-48. DOI: https://doi.org/10.2307/2227401

Rostow, W. W. (1963). Las etapas del crecimiento económico: un manifiesto no comunista. México D.F., México: Fondo de Cultura Económica.

Soza Amigo, S. (2007). Análisis estructural input-output: antiguos problemas y nuevas soluciones. Oviedo: Universidade de Oviedo.

Taylor, M. (2007). Rethinking the global production of uneven development. Globalizations, 4(4), 529-542. DOI: https://doi.org/10.1080/14747730701695794

Vence Deza, X., e González López, M. (2009). Los servicios a empresas intensivos en conocimiento y los flujos externos de conocimiento en los sistemas de innovación abiertos: el caso de Galicia. Ekonomiaz. Revista Vasca de Economía, 70, 184-205. Recuperado de: https://www.euskadi.eus/web01a2reveko/es/k86aEkonomiazWar/ekonomiaz/abrirArticulo?idpubl=65\&registro=967 
Vence Deza, X., e Rodil Marzábal, O. (2002). La balanza de pagos tecnológicos de Galicia: entre la dependencia y la irrelevancia tecnológicas. Revista Galega de Economía, 11(1), 1-25.

Recuperado de: https://www.redalyc.org/articulo.oa?id=39111111

Villaverde López, G. (2014). Estructura y deixis. La teoría kantiana de la objetividad en el horizonte de la época moderna. (Tese de doutoramento). Madrid: Universidad Complutense de Madrid.

Recuperado de: https://eprints.ucm.es/27230/

Waugh, F. V. (1950). Inversion of the Leontief Matrix by power series. Econometrica, 18(2), 142-154.

DOI: https://doi.org/10.2307/1907265 